\title{
A Fungal Effector With Host Nuclear Localization and DNA-Binding Properties Is Required for Maize Anthracnose Development
}

\author{
Walter A. Vargas, ${ }^{1}$ José M. Sanz-Martín, ${ }^{1}$ Gabriel E. Rech, ${ }^{1}$ Vinicio D. Armijos-Jaramillo, ${ }^{1}$ \\ Lina P. Rivera, ${ }^{1}$ María Mercedes Echeverria, ${ }^{2}$ José M. Díaz-Mínguez, ${ }^{1}$ Michael R. Thon, ${ }^{1}$ and \\ Serenella A. Sukno' \\ ${ }^{1}$ Instituto Hispano-Luso de Investigaciones Agrarias (CIALE), Departamento de Microbiología y Genética, Universidad de \\ Salamanca, 37185 Villamayor, Spain; ${ }^{2}$ Facultad de Ciencias Agrarias, Universidad Nacional de Mar del Plata - C.C. 276 (7620) \\ Balcarce, Buenos Aires, Argentina
}

Submitted 15 September 2015. Accepted 10 November 2015.

\begin{abstract}
Plant pathogens have the capacity to manipulate the host immune system through the secretion of effectors. We identified 27 putative effector proteins encoded in the genome of the maize anthracnose pathogen Colletotrichum graminicola that are likely to target the host's nucleus, as they simultaneously contain sequence signatures for secretion and nuclear localization. We functionally characterized one protein, identified as CgEP1. This protein is synthesized during the early stages of disease development and is necessary for anthracnose development in maize leaves, stems, and roots. Genetic, molecular, and biochemical studies confirmed that this effector targets the host's nucleus and defines a novel class of double-stranded DNA-binding protein. We show that CgEP1 arose from a gene duplication in an ancestor of a lineage of monocot-infecting Colletotrichum spp. and has undergone an intense evolution process, with evidence for episodes of positive selection. We detected CgEP1 homologs in several species of a grass-infecting lineage of Colletotrichum spp., suggesting that its function may be conserved across a large number of anthracnose pathogens. Our results demonstrate that effectors targeted to the host nucleus may be key elements for disease development and aid in the understanding of the genetic basis of anthracnose development in maize plants.
\end{abstract}

Colletotrichum is a large genus of Ascomycete fungi that infect a wide variety of plants, including important crop plants such as maize, wheat, sorghum, and soybean (Bailey and Jeger 1992; Prusky et al. 2000). Many Colletotrichum species infect plants by means of an intracellular hemibiotrophic lifestyle in which biotrophic hyphae penetrate the plant cell wall and

M. R. Thon and S. A. Sukno authors contributed equally to this work.

Current address for W. A. Vargas: Centro de Estudios Fotosintéticos y Bioquímicos-CONICET, Suipacha 570, Rosario, 2000 Argentina.

Corresponding authors: S. A. Sukno; E-mail: ssukno@usal.es and M. R. Thon; E-mail: mthon@usal.es

*The $\boldsymbol{e}$-Xtra logo stands for "electronic extra" and indicates that thirteen supplementary figures and five supplementary tables are published online.

๑) 2016 The American Phytopathological Society grow between the cell wall and the plasma membrane without breaching the membrane. Later, the biotrophic hyphae give rise to necrotrophic hyphae that kill plant cells, probably through the release of toxins and lytic enzymes (Bergstrom and Nicholson 1999; Gan et al. 2013; O'Connell et al. 2012).

Maize anthracnose is caused by Colletotrichum graminicola, which is a model for hemibiotrophic plant pathogens (Bergstrom and Nicholson 1981; Crouch and Beirn 2009; Perfect et al. 1999). The infection process begins when spores germinate on the epidermis and form dome-shaped appressoria that enter the plant cells, using a combination of mechanical force and the highly regulated secretion of degradative enzymes that are implicated in the weakening of the plant cell wall (Kleemann et al. 2008; O'Connell et al. 2012). After appressorium formation, the penetration of the epidermal cells is achieved by the development of a thin penetration peg that later gives rise to the characteristic primary hyphae (Mims and Vaillancourt 2002; Politis and Wheeler 1972). Inside the host's cells, this irregularly shaped primary hypha grows biotrophically and can form one or more branches spreading to adjacent cells. This stage of infection is referred to as the biotrophic phase, since the penetrated host cells remain alive. The enlarged surface area between the host membrane and the fungus favors the exchange of molecules that allow fungal growth and counteract the plant immune system (Micali et al. 2011; O'Connell et al. 2012; Panstruga 2003; Perfect and Green 2001).

In general, the establishment of intracellular biotrophy by fungal pathogens requires the deployment of an arsenal of effectors that interfere with the normal physiological processes of the host cell, especially immune responses (Irieda et al. 2014; Kleemann et al. 2012; Rivas and Genin 2011). When a pathogenic microorganism attacks, the plant immune system is activated by the recognition of microbial molecules called pathogen-associated molecular patterns (PAMPs) through pattern-recognition receptors in plant cells (Jones and Dangl 2006). This mechanism for microbial recognition represents the plant's basal defense and is responsible for PAMP-triggered immunity (PTI) in plants. To counteract plant immunity, pathogens have evolved specialized effector proteins that are delivered into the host cells to suppress plant defenses and elicit effector-triggered susceptibility (ETS). Alternatively, in some cases, plants developed proteins for recognition of effectors (such as nucleotide binding-leucinerich repeat proteins) that activate effector-triggered immunity, an amplified version of PTI, that prevents pathogenic 
infection (Jones and Dangl 2006). The study of microbial effector proteins has become an active field of research to better understand the plant immune system and the molecular mechanisms triggered in the host cells during the early stages of plant microbe interactions.

In hemibiotrophic fungi, the biotrophic hypha has been shown to be important for the release of effector proteins into plant cells during early stages of host infection (Irieda et al. 2014; Khang et al. 2010; Kleemann et al. 2012; Yi and Valent 2013). In general terms, effectors are defined as "molecules secreted by plant-associated organisms that alter host-cell structure and function" (Hogenhout et al. 2009). Our knowledge of the role of fungal effectors during plant infection is still limited. Recent reports have revealed that effector proteins are delivered into the host cells and, then, travel to various subcellular compartments, such as mitochondria, chloroplasts, nuclei, nucleoli, and other intracellular bodies (Petre et al. 2015; Win et al. 2012). There are several examples of effectors characterized in sufficient detail to the point that we have knowledge of their translocation and function in host cells (Irieda et al. 2014; Khang et al. 2010; Mentlak et al. 2012). Colletotrichum gloeosporioides $\mathrm{CgDN} 3$ is the first protein identified in a phytopathogenic fungus that suppresses host defense responses (Stephenson et al. 2000). The protein is weakly similar to the extracellular domain of a family of plant cell-wall receptor kinases and is localized to biotrophic intracellular infection vesicles in infected host cells. Null mutants form conidia, which produce appressoria on intact host surfaces, but further growth is limited to the formation of intracellular primary vesicles. However, wounded leaf surfaces are colonized necrotrophically by these mutants. These results suggest the involvement of $\mathrm{CgDN} 3$ in the formation and maintenance of biotrophic hyphae within cells of compatible Stylosanthes guianensis leaves colonized by $C$. gloeosporioides.

Effector proteins from plant-pathogenic viruses, bacteria, and nematodes are known to be localized to the plant nucleus, in which they target plant components that are needed for defense responses (Rivas and Genin 2011). Phytopathogenic fungi also have been shown to deliver effectors to the plant nucleus (Kemen, et al. 2005; Petre et al. 2015, Redkar et al. in press). The UfRTP1 gene from Uromyces fabae encodes a protein that is predicted to contain a nuclear localization signal (NLS), and immunolocalization studies showed that it is translocated into the nuclei and cytoplasm of infected host cells (Kemen et al. 2005). This protein is a member of a conserved family of cysteine protease inhibitors (Pretsch et al. 2013). It is the first fungal protein that has been shown to be secreted from the fungus and localized to the plant nucleus. In addition to their role in plant pathogenic fungi, nuclear effectors were also shown to be important for symbiotic associations in root-mycorrhiza interactions (Kloppholz et al. 2011; Plett et al. 2011).

To better understand the number and diversity of nuclear effectors in the maize anthracnose fungus Colletotrichum graminicola, we conducted an in silico study and identified 27 candidate effector proteins likely to target the host nucleus, as they have both a signal peptide for secretion and a NLS. We characterized one candidate through phylogenetic and functional assays. We show that this effector likely arose from a gene duplication event in the common ancestor of a grass-infecting clade of Colletotrichum spp., and then, underwent rapid evolutionary remodeling, including the formation of intragenic tandem repeats (ITR) that contain NLS. Genetic, molecular, and biochemical studies confirmed that CgEP1 is essential for host invasion and disease development and defines a novel class of DNA-binding proteins that target host genomic DNA and may be involved in regulatory processes preventing host-defensive responses against plant pathogens.

\section{RESULTS}

\section{Identification of putative nuclear effectors} in C. graminicola.

Host nuclear effector proteins are characterized by the simultaneous presence of secretion signals (SS) and NLS (Bellafiore et al. 2008; Rivas and Genin 2011). Therefore, we searched the $C$. graminicola genome for proteins that contain a secretion signal peptide, using SignalP, and identified 1,347 putative extracellular proteins. The signal peptide was removed from the protein sequence, using SignalP, and the mature proteins were scanned with NLStradamous and Wolf-PSORT, which identified 91 and 164 proteins, respectively, that contain putative NLS. A total of 27 proteins were predicted to have NLS by both programs (Table 1).

Four of the predicted nuclear effector proteins are speciesspecific, as they have no significant sequence similarity to proteins from other species of fungi (Table 1). Among the predicted nuclear effectors with conserved domains, we found enzymes with varying functions, such as protein kinases, proteases, chaperone-like proteins, glycosidases, and a homolog to necrosis-inducing proteins. While the functional characterization and subcellular localization of these putative effectors remains to be confirmed, these results suggest that many of the proteins produced by these fungi have the potential to reach the host nucleus and modify important cellular processes, such as protein turnover and pathogenesis-related signal transduction events. Sixteen (59\%) are hypothetical proteins with unknown function and no conserved functional domains (Table 1). Nine of the proteins have an isoelectric point higher than 9 , similar to many proteins with nuclear functions and nucleic acid interactions, such as histones and other regulatory proteins (Brusch 2012; Marian et al. 2003; Thomas and Travers 2001) (Table 1).

We performed a BLAST search of the 27 candidate nuclear effectors in the Pathogen-Host Interactions Database (PHIBase), to determine whether any of the proteins have similarity to effectors identified in other organisms. Four proteins have significant similarities to entries in the database. Protein GLRG_00260 is a homolog of MoCDIP4 (E = 8.46e-45), a glycoside hydrolase from Magnaporthe oryzae, which has been reported to be an effector that induces cell death in rice (Chen et al. 2013). Protein GLRG_02846 is homologous to MGG_01748 an aspartic protease from $M$. oryzae $(\mathrm{E}=1.23 \mathrm{e}-129)$, a null mutant of which has reduced virulence (Jeon et al. 2007). GLRG_05523 is homologous to NPP1 (E =7.24e-26), an effector from Hyaloperonospora arabidopsidis (Fellbrich et al. 2002). The last protein with matches in PHI-Base is GLRG_10691. This protein is homologous to Fusarium graminearum FGSC_12132 (E = 0), a protein kinase that is lethal when deleted (Wang et al. 2011).

One putative nuclear effector, GLRG_04079, contains no conserved domains and is composed of almost perfect ITR, with each repeat consisting of a basic (Lys-rich) and acidic (Asp/Glu-rich) region (Fig. 1). Proteins with ITR are known to play roles in the activation of immune responses in animals and may have similar roles in plant pathogens (Hood et al. 1996; Rich and Ayala 2000). Therefore, we selected GLRG_04079 for further study. Interestingly, two previously described effector proteins, Ecp6 from Cladosporium fulvum (Bolton et al. 2008) and SP7 from Glomus intraradices (Kloppholz et al. 2011), also contain ITR. The ITR sequences in GLRG_04079 bear no similarity to the repetitive domains in Ecp6 or SP7, suggesting independent origins of the genes. Also, the protein encoded by GLRG_04079 has a predicted isoelectric point (9.5) similar to histones and other DNA-binding proteins from maize (Brusch 2012; Marian et al. 2003). Previous transcriptomic analyses revealed that GLRG_04079 is expressed during early stages of maize infection, suggesting that it has an 
important role during the infection process (O'Connell et al. 2012). We named this putative effector CgEP1 (Colletotrichum graminicola effector protein 1).

\section{Diversity, allelic variations, and adaptive evolution of CgEP1 in Colletotrichum species.}

The deduced amino acid sequence for CgEP1 shows that it is a highly basic protein that, based on BLAST searches of the GenBank nr database, is unique to $C$. graminicola. The coding region of CgEP1 was cloned and sequenced from 16 isolates of C. graminicola (collected in North and South America, Africa, Europe, and Asia) as well as from representative isolates of other Colletotrichum species (Supplementary Table S1). In the 16 isolates of $C$. graminicola, CgEP1 occurs in three main allelic forms (A, B, and $\mathrm{C}$ ), which differ in the number of repeat units (Fig. 1) and are present as a single-copy gene, as demonstrated by Southern blot analysis (Supplementary Fig. S1). Further cloning and sequencing confirmed that CgEP1 is highly conserved in Colletotrichum spp. belonging to the Graminicola clade, which is comprised of species that infect monocot plants (C. sublineola, C. falcatum, C. cereale, C. echinochloae, and
C. navitas, pathogens of sorghum, sugar cane, wheat, barnyard millet, and prairie grasses, respectively) (Crouch and Beirn 2009). Polymerase chain reaction (PCR) amplification and sequencing of the $\mathrm{CgEP} 1$ orthologs from $C$. sublineola, $C$. falcatum, and $C$. cereale revealed that the loci are nearly identical at the DNA level. For example, the C. cereale locus has $98.5 \%$ similarity to the $C$. graminicola locus (not shown). In contrast, CgEP1 is not present in the genomes of $C$. higginsianum, C. orbiculare, C. gloeosporioides, C. simmondsii, or C. fioriniae. This result was further confirmed with Southern blot experiments that included DNA samples from species outside the Graminicola clade $(C$. lindemuthianum, $C$. boninense, and C. coccodes).

Based on sequence analyses of the allelic variations, we hypothesize that CgEP1 has undergone rapid evolution and an intense selective pressure that likely led to duplications of complete repeats and specific amino acid substitutions (Supplementary Fig. S3). Traces of adaptive evolution were evident in the same codon within each repeat (Fig. 1; Supplementary Fig. S4; Supplementary Table S2). These residues may be crucial for CgEP1-target binding or recognition and, thus, relevant for the arms race

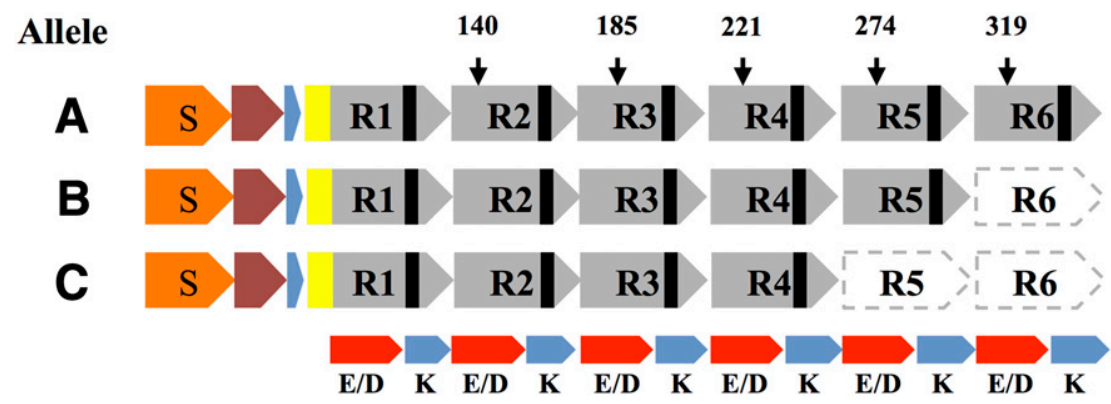

Fig. 1. CgEP1 sequence and organization of the intragenic tandem repeats (ITR). Schematic representation of the three alleles of CgEP1 in the isolates from the Graminicola clade. Each protein is composed of four to six nearly identical repeat units (R). Black shading indicates a nuclear localization signal; red arrows, the acidic motif (E/D); blue arrows, the alkaline motif (K), S = signal peptide for secretion; blue shading, the nonrepetitive $\mathrm{N}$-terminal (including a short basic Lys-rich motif). Common to all the alleles there is a sequence insertion in R1, indicated by yellow shading. Arrows indicate position of residues with evidence for positive selection.

Table 1. Colletotrichum graminicola proteins with predicted secretion and nuclear localization signals

\begin{tabular}{|c|c|c|c|c|}
\hline Gene ID & Description & AA & Ip & InterProScan \\
\hline GLRG_00260 & Fungal cellulose binding domain-containing protein & 300 & 9.57 & Glycoside hydrolase family 61 \\
\hline GLRG_00965 ${ }^{\mathrm{a}}$ & Hypothetical protein & 241 & 10.88 & No InterProScan Results \\
\hline GLRG_01283 & Hypothetical protein & 431 & 9.97 & No InterProScan Results \\
\hline GLRG_02481 & Hypothetical protein & 62 & 11.30 & No InterProScan Results \\
\hline GLRG_02617 & Hypothetical protein & 228 & 4.62 & No InterProScan Results \\
\hline GLRG_02846 & Eukaryotic aspartyl protease & 829 & 4.73 & Peptidase A1 \\
\hline GLRG_03517 & Hypothetical protein & 351 & 6.67 & No InterProScan Results \\
\hline GLRG_03901 & Hypothetical protein & 369 & 9.06 & No InterProScan Results \\
\hline GLRG_04079 & Hypothetical protein & 328 & 10.52 & No InterProScan Results \\
\hline GLRG_05523 & Necrosis inducing protein & 359 & 5.98 & Necrosis inducing protein \\
\hline GLRG_05544 & Hypothetical protein & 165 & 10.74 & No InterProScan Results \\
\hline GLRG_06153 & Hypothetical protein & 425 & 7.08 & No InterProScan Results \\
\hline GLRG_06254 & Hypothetical protein & 487 & 10.98 & No InterProScan Results \\
\hline GLRG_06454 & DnaJ domain-containing protein & 400 & 10.04 & Heat shock protein DnaJ, N-terminal \\
\hline GLRG_07140 & Hypothetical protein & 254 & 7.92 & No InterProScan Results \\
\hline GLRG_07195 & Hypothetical protein & 207 & 3.89 & No InterProScan Results \\
\hline GLRG_07420 & Gpi16 subunit & 561 & 5.39 & Gpi16 subunit, GPI transamidase component \\
\hline GLRG_08161 & Hypothetical protein & 285 & 11.36 & Cell wall galactomannoprotein \\
\hline GLRG_08510 ${ }^{\mathrm{a}}$ & Hypothetical protein & 409 & 5.40 & No InterProScan Results \\
\hline GLRG_10514 ${ }^{\mathrm{a}}$ & Hypothetical protein & 202 & 4.69 & No InterProScan Results \\
\hline GLRG_10691 & Hypothetical protein & 1,178 & 6.88 & Protein kinase, catalytic domain \\
\hline GLRG_10693 & DEK C terminal domain-containing protein & 236 & 8.46 & SWIB/MDM2 domain \\
\hline GLRG_10695 & Hypothetical protein & 331 & 6.73 & No InterProScan Results \\
\hline GLRG_10986 & oxalate decarboxylase family bicupin & 449 & 5.62 & RmlC-like cupin domain \\
\hline GLRG_11207 & Hypothetical protein & 147 & 9.02 & No InterProScan Results \\
\hline GLRG_11501 & Hypothetical protein & 681 & 9.03 & Tyrosinase \\
\hline GLRG_11533 & glucosidase II beta subunit-like protein & 541 & 4.64 & Mannose-6-phosphate receptor binding domain \\
\hline
\end{tabular}

\footnotetext{
${ }^{a}$ Proteins with no homology to proteins in the GenBank nr database $(E$ value threshold $=1 \mathrm{e}-5)$.
} 
between host and the pathogen, reinforcing the importance of this effector during anthracnose development in grasses (Kanzaki et al. 2012).

A BLAST search revealed that the N-terminus of CgEP1 has strong similarity to another protein from the $C$. graminicola genome, with the locus ID GLRG_09337. Homologs of GLRG_09337 were subsequently identified in other members of genus Colletotrichum, both within and outside the Graminicola clade. The $\mathrm{N}$ terminal 45 residues of CgEP1 have $66 \%$ identity to GLRG_09337 and have 55 to $57 \%$ identity to the GLRG_09337 orthologs from other Colletotrichum spp. (Supplementary Fig. S5A). GLRG_09337 and its orthologs share highly conserved $\mathrm{N}$ and $\mathrm{C}$ termini, separated by a lysine- and asparagine-rich and highly variable central domain. In addition, GLRG_09337 (as well as its orthologs) and CgEP1 share an intron, located in the same position in both genes. A dotplot of GLRG_09337 and CgEP1 revealed that the repeat units of CgEP1 have 36\% identity to a portion of GLRG_09337 (Supplementary Fig. S6A). This evidence indicates that CgEP1 and GLRG_09337 are paralogs, related by a gene duplication event in an ancestor of the Graminicola clade. Following the gene duplication, the CgEP1 gene structure was remodeled by mutations and intragenic duplication of a region that now forms the intragenic repeats of $\mathrm{CgEP} 1$. An analysis of previously published transcriptional profiling experiments shows that both CgEP1 and GLRG_09337 are expressed at early stages of infection and display similar patterns of expression (O'Connell et al. 2012).

Additional genes encoding proteins with structural similarities to CgEP1 were also in the genomes of M. oryzae, Trichoderma virens, Gaeumannomyces graminis, and Thielavia terris. These proteins lack sequence similarity to CgEP1 but are highly basic, have intragenic tandem repeats, and have multiple NLS. An important characteristic of this group of proteins is that they have repeat units with a characteristic distribution of acidic and basic residues. Structural analyses and folding predictions suggested that each repeat unit in $\mathrm{CgEP} 1$ and other repeatcontaining proteins fold into a secondary structure resembling a bipolar $\alpha$-helix. Bipolar helices with strong acidic and basic $\mathrm{N}$ - and C-termini, respectively, might be important for structural stabilization.

\section{CgEP1 is a novel class of pathogenicity factor targeted to the host nucleus.}

Maize leaf infection by $C$. graminicola is initiated by a biotrophic stage (with characteristic primary hyphae) for approximately $48 \mathrm{~h}$, followed by a transition (between 48 and $72 \mathrm{~h}$ postinoculation [hpi]) into the necrotrophic lifestyle in which
A

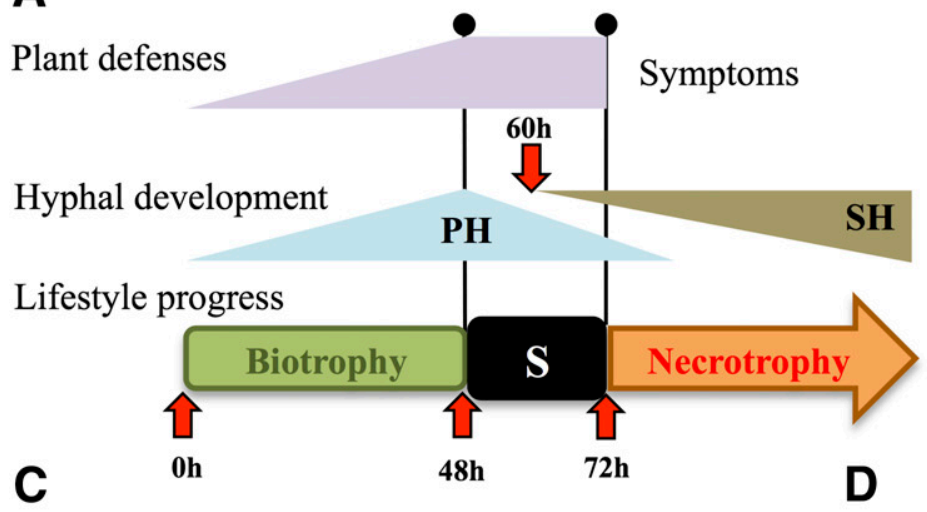

B

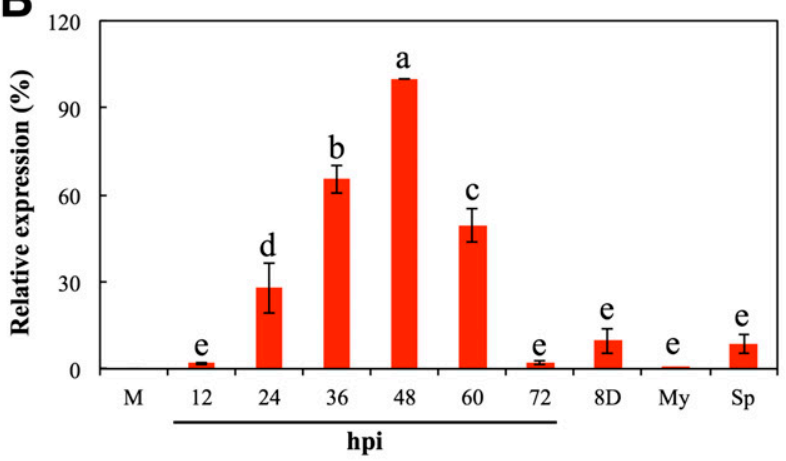

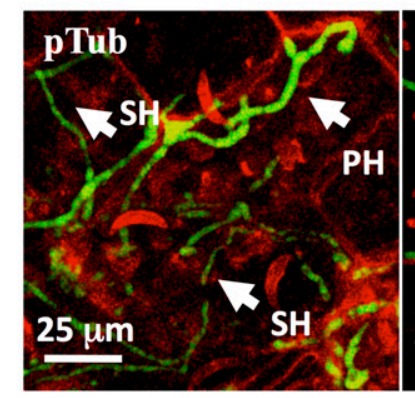
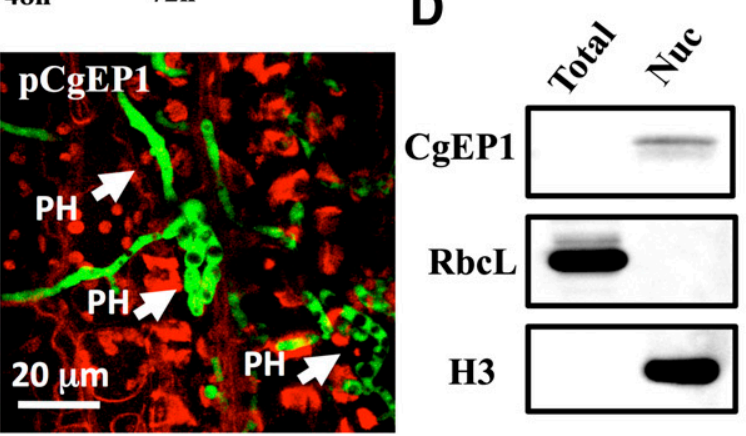

$\mathbf{E}$

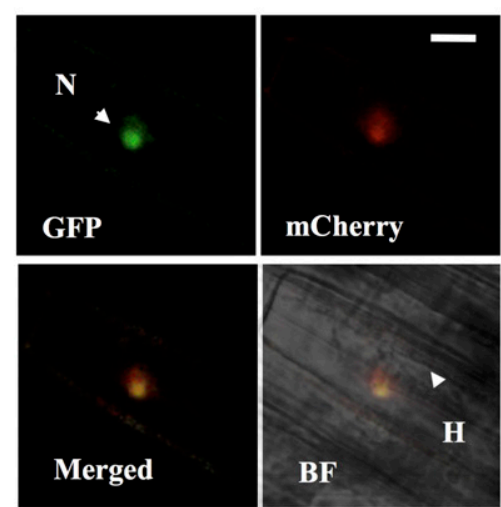

Fig. 2. CgEP1 is expressed in primary hyphae and targets the host nucleus. A, Schematic representation summarizing the hallmark events of anthracnose leaf blight in maize. Pathogenesis starts with a biotrophic stage that lasts $48 \mathrm{~h}$ (mainly primary hyphae are developed by the pathogen). A transition process ( $\mathrm{S}$ ) into the necrotrophic lifestyle begins $48 \mathrm{~h}$ postinoculation (hpi) and is complete by $72 \mathrm{hpi}$ (Vargas et al. 2012). B, Expression of CgEP1 determined every 12 hpi up to $72 \mathrm{hpi}$ and in necrotic tissue 8 days postinoculation (8D) containing sporulating fungal mycelium, fungal mycelium grown in vitro (My), and spores (Sp), by reverse transcription quantitative polymerase chain reaction. $\mathrm{M}=$ mock-inoculated leaves. Expression levels were normalized to mean expression level for $\beta$-tubulin and histone H3. Letters indicate statistically significant differences according to a Tukey's honestly significant differences test. C, The fluorescence signal is detected only in primary hyphae (PH) when the reporter gene green fluorescent protein (GFP) is fused to the promoter region of CgEP1, while both primary and secondary hyphae (SH) expressed GFP when fused to the promoter region of a constitutive gene. Confocal micrographs were taken 65 hpi. Fungal development for both strains was confirmed after lactophenol blue staining. Bars $=30 \mu \mathrm{m}$. D, Western blotting assay using total and nuclear protein extracts revealed that $\mathrm{CgEP} 1$ colocalizes with histone $\mathrm{H} 3$. As control for cytosolic contamination, antibodies against rubisco large subunit (RbcL) were used. Due to the high concentration of rubisco in total and histone $\mathrm{H} 3$ in nuclear extracts, only $3 \mu \mathrm{g}$ of protein was loaded in each lane and the film exposition was controlled, in order to avoid signal saturation. As a result signals for CgEP1 or histone H3 were under the detection limit in the total protein preparation. E, The nuclear localization of CgEP1 was confirmed using a translational fusion of this effector and the reporter gene mCherry (ID1 strain) and maize transgenic plants with GFP-tagged nuclei (colocalization of mCherry and GFP). This figure is a representative micrograph from one infection site from independent experiments. $\mathrm{N}=$ nucleus, $\mathrm{A}=$ appressoriun, $\mathrm{H}=$ hyphae, and $\mathrm{Bars}=25 \mu \mathrm{m}$. 
secondary hyphae colonize dead cells (Fig. 2A) (O'Connell et al. 2012; Vargas et al. 2012). A time-course gene-expression analysis revealed that mRNA for CgEP1 is primarily accumulated during the biotrophic phase with a maximum expression 48 hpi (Fig. 2B). CgEP1 expression is evident in ungerminated spores, suggesting a requirement for the protein immediately upon (or perhaps even before) penetration. Low levels of expression are still evident in lesions at $72 \mathrm{~h}$ and $8 \mathrm{~d}$ after inoculation. The lesions at these time points are primarily comprised of necrotrophic hyphae, however, lesion margins still contain biotrophic hyphae, which may lead to residual detection of CgEP1 transcripts. For in situ confirmation of CgEP1 expression, we constructed a $C$. graminicola strain (strain A1 and B1) containing a transcriptional fusion between the promoter region of CgEP1 and the green fluorescent protein (GFP) reporter gene (Supplementary Fig. S7). Confocal microscopy of infection sites 65 hpi, revealed that GFP was only detected in the primary hyphae, while no secondary hyphae displaying GFP signal were found (Fig. $2 \mathrm{C})$. As a control, we also prepared a transcriptional fusion between the promoter region of the $\beta$-tubulin gene and GFP. In this case, GFP fluorescence was detected in both primary and secondary hyphae (Fig. 2C). Together, these results demonstrate that the expression of CgEP1 is specifically activated in primary hyphae during the biotrophic stage.

To functionally characterize the predicted SS and NLS of CgEP1, we sought to determine the fate of the protein during host infection. First, to confirm that the protein is secreted, we constructed fungal strains that constitutively expressed $\mathrm{CgEP} 1$ in saprophytic culture. Using these strains, we detected the presence of CgEP1 in culture filtrates, using anti-CgEP1 antibody (Supplementary Fig. S8C). To assess the subcellular localization of CgEP1 during leaf infection, protein extracts prepared from nuclear fractions and from infection sites were used for immunodetection of CgEP1 by Western blotting. We identified a protein band with the expected size for CgEP1 in the nuclear fraction, while no protein band was present in the total extract. We surmise that the amount of CgEP1 in the total extract was below the detection limit (Fig. 2D).

To further study the subcellular localization of CgEP1 at the early stages of disease development, we sought to investigate the fate of a CgEP1::mCherry translational fusion. However, the expression of translational fusions in fungal cells to track the effector's localization inside the host has been precluded by the low expression levels achieved by the native promoter of effectors (Kleemann et al. 2012; Win et al. 2012). In order to circumvent this issue, we developed $C$. graminicola strains that express the translational fusion (CgEP1::mCherry) under the control of the Aspergillus nidulans pgdA constitutive promoter (Supplementary Fig. S9) and, then, tracked mCherry fluorescence during infection. To avoid high levels of red chlorophyll autofluorescence in leaves, we conducted the infection assays using leaf sheaths of maize plants expressing a Histone $1 \mathrm{~B}:$ :GFP translational fusion (plants with GFP-tagged nuclei, Construct ID 1025; J. Craig Venter Institute's Maize Cellgenomics database). Confocal micrographs confirmed the nuclear localization of CgEP1, as the mCherry fluorescence signal colocalized with the GFP signal inside maize nuclei (Fig. 2E; Supplementary Fig. S10). Together, these assays allowed us to confirm that, after being synthesized in $C$. graminicola cells, CgEP1 reaches the host nucleus during disease development.

To study the role of CgEP1 in anthracnose development, we performed pathogenicity tests using a $C$. graminicola lacking CgEP1. We prepared CgEP1-knockout strains (Ko14 and Ko20), which also express GFP, to facilitate microscopic assays (Supplementary Fig. S11). The pathogenicity assays revealed that CgEP1 is essential for anthracnose development in leaves, stalks, and roots. In all cases, no hyphae were detected by confocal microscopy, when the tissues were inoculated with the mutant strains. (Fig. 3A to E). The importance of CgEP1 for disease was confirmed in Ko14-C strains, after the wild-type version of CgEP1 was restored to the Ko14 strain (Figs. 3 and 4).

Histological studies of leaf blight infection sites showed that CgEP1 is essential for $C$. graminicola to infect intact host tissue, as the Ko14 mutant strain was only able to infect the host after the epidermal cell layer was removed by wounding (Fig. $4 \mathrm{~A}$ to $\mathrm{D})$. This finding suggests that CgEP1 functions in the epidermal cell layer, enabling entrance of fungal hyphae into the host. Further histological studies revealed that, when Ko14 attempts to infect maize leaves, a strong plant-defensive response was detected. This response includes the accumulation of reactive oxygen species and phenolic compounds, as evidenced by diaminobenzidine staining and leaf autofluorescence, respectively (Fig. 4E to $\mathrm{H}$ ). Further microscopic studies suggested that CgEP1 is necessary to cope with host defense responses rather than being involved in host penetration. Appressoria formation assays on cellophane membrane revealed that the Ko14 strain develops functional appressoria that reach the pressure needed for membrane penetration (Fig. 4M and N). However, microscopic observations revealed that, during host infection, the invasion process of the Ko14 strain is interrupted when a penetration peg attempts to enter the host epidermis (Fig. 40 and P). The wild-type strain developed hyphae in $93 \%$ of the appressoria observed, while no hyphae developing appresoria were observed with Ko14 strain. Overall, these observations indicate that $\mathrm{CgEP} 1$ is necessary to attenuate primary defensive responses in host epidermal cells and is essential for host invasion and disease development (Fig. 4E to $\mathrm{H}$ ). Collectively, these results show that CgEP1 is a novel class of nuclear effector that is essential at the early stages of anthracnose development in maize.

\section{CgEP1 binds to maize genomic DNA.}

To further investigate the role of CgEP1, we sought to identify the nuclear targets of this effector. First, we confirmed by Western blotting that CgEp1 is involved in the formation of nuclear supramolecular complexes with genomic DNA, as evidenced by band supershift of the effector after the induction of protein cross-linking, using formaldehyde in maize infection sites (Fig. 5A). Several attempts of protein pull-down assays (using anti-CgEP1) had negative results, suggesting that the band supershift was due to CgEP1-DNA complexes. To identify host genomic regions that could be candidate targets for CgEP1 binding, we performed chromatin immunoprecipitation analyses followed by DNA cloning (ChIP-cloning) (Torres et al. 2008) (Supplementary Fig. S12). After cloning, Escherichia coli transformation, and plasmid sequencing, we obtained sequences of 35 clones. The binding of CgEP1 to the cloned DNA fragments was further confirmed by in vitro protein-DNA binding experiments, using a recombinant version of the protein expressed in E. coli (Fig. 5B, Supplementary Fig. S13). The protein-DNA interaction assays revealed that the free protein has reduced mobility compared with the complexes with DNA in native gels. This effect can be explained by the high positive charge of $\mathrm{CgEP} 1$, which is reduced or neutralized after binding DNA molecules, and increases the mobility of the complexes. This hypothesis was confirmed when the complexes were cross-linked using formaldehyde and were subjected to sodium dodecyl sulfate-polyacrylamide gel electrophoresis (SDSPAGE). Under such conditions, the mobility of complexes is independent of protein charge and both the protein-DNA complexes and free protein are resolved according to molecular size. An interesting aspect of the interaction is that CgEP1 is able to bind both maize genomic fragments as well as salmon sperm DNA (Fig. 5), which points to a nonspecific binding 
mechanism. The importance of the CgEP1 charge for DNA binding was further confirmed by the fact that $\mathrm{pH}$ increments above the predicted isoelectric point of the protein are detrimental for the interaction (Fig. 5C and D).

We aligned the cloned sequences to the $Z$. mays genome using MEGABLAST and found that 29 of the clones aligned to the genome with an E-value of less than $1 \times 10^{-15}$, and percent identity greater than $98 \%$. Many of the clones aligned to the genome at multiple locations and we identified a total of 846 loci in the genome that match the cloned fragments. To determine whether CgEP1 binds to the promoter regions of genes, thus potentially affecting their transcription, we prepared a BLAST database of the DNA sequences 2000 bases upstream of the translational start site of the Zea mays gene models. We performed a MEGABLAST search using the clone sequences, limiting the search to the top five hits from each sequence, and identified 58 genes (Supplementary Table S3). Fifty of the genes $(86 \%)$ encode uncharacterized proteins, many of which have no known functional domains. Four proteins are putative transcription factors (TFs). The remaining four with known functions are a proteasome subunit, a serine/threonine protein phosphatase, a glycosyltransferase subunit, and a mitogenactivated protein kinase kinase kinase. These 58 genes are candidates for being transcriptionally regulated by $\mathrm{CgEP} 1$.

\section{DISCUSSION}

The study of host-nuclear targeted effectors are of great interest, since these proteins might have a direct effect on nuclear processes, such as DNA replication, gene expression regulation, or epigenetic effects on host chromatin. Similar to bacterial nucleomodulins or TAL effectors (Bierne and Cossart 2012; Bogdanove and Voytas 2011), these proteins are likely to take over important physiological processes during fungal pathogenesis to favor plant disease development. In a genomewide survey to detect proteins containing both NLS and SS domains, we identified 27 candidate nuclear effector proteins in C. graminicola. This catalog of putative effectors offers the starting point for future studies aimed to uncover the role of nuclear effectors in host-microbe interactions.

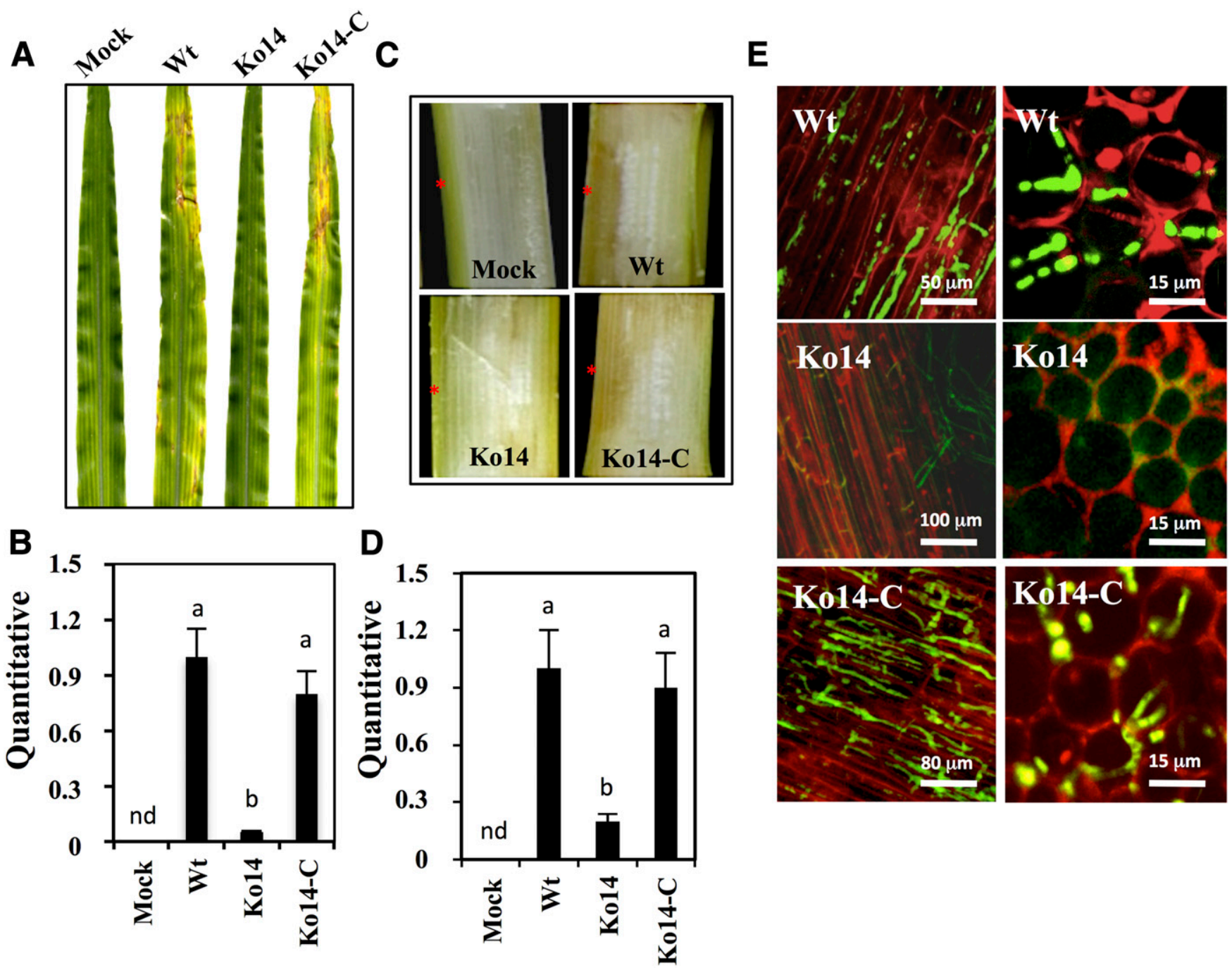

Fig. 3. The nuclear effector CgEP1 is not tissue-specific. A, Anthracnose leaf blight development by Colletotrichum graminicola wild type (Wt), the mutant Ko14, and the complemented mutant Ko14-C (clone 2B). Fungal spores were sprayed on the surface of leaves and were photographed $96 \mathrm{~h}$ postinoculation (hpi). B, Quantitative analysis of disease development as estimated by lesion size measurement $72 \mathrm{hpi}$. Bars represent the mean value for three biological replicates \pm standard deviation (SD). Bars with different letters differ significantly according to Tukey's honestly significant differences (HSD) test at a significance level of $0.5 \%$. C, In vitro stalk rot development by the three C. graminicola strains 3 days postinoculation. Red asterisks indicate the point of inoculation. D, Quantitative analysis of disease development as estimated by the extent of discoloration beneath the infection site. Bars represent the mean value for three biological replicates \pm SD. Bars with different letters differ significantly according to Tukey's HSD test at a significance level of $0.5 \%$. E, Root infection assays using the Wt, Ko14, and Ko14-C. Root samples were collected $96 \mathrm{hpi}$, were stained with propidium iodide, and were photographed with a confocal microscope. 
We characterized one putative effector, i.e., CgEP1, that defines a family of pathogenicity factors with nuclear localization and double-stranded DNA-binding properties. CgEP1 is a highly basic protein with an evolutionarily conserved N-terminal region followed by ITR that are predicted to fold into a bipolar helix structure. We found three CgEP1 alleles that vary in the number of ITR. Variation in the number of ITR among isolates may convey diversity in either function, specificity, or both. Variation in intragenic repeats is known to affect the activation of immune responses caused by animal pathogens and may play
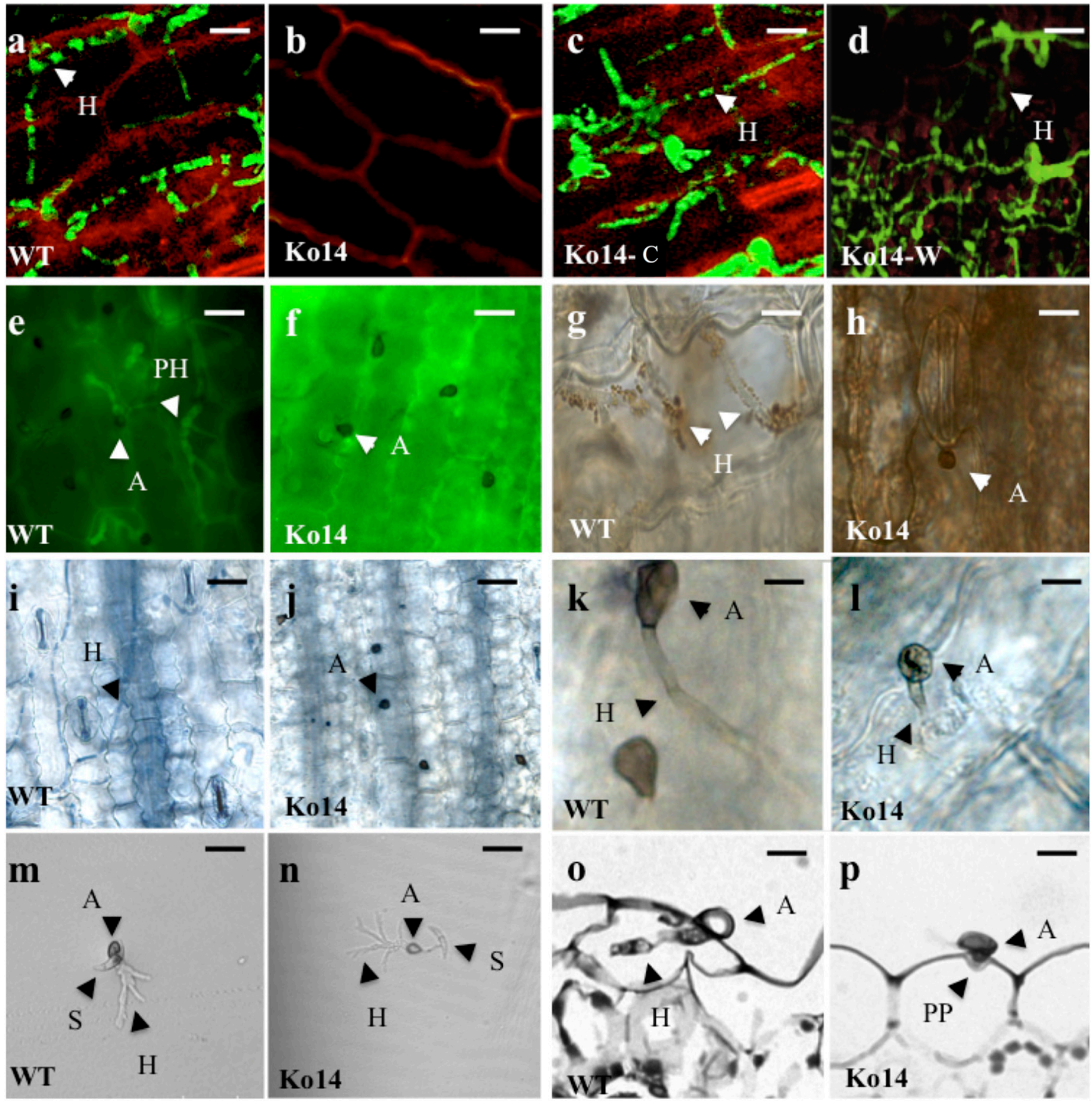

p

Fig. 4. The CgEP1 mutant strain Ko14 is not able to penetrate epidermal maize cells. A to D, Confocal microscopy of infection sites on maize leaves. Micrographs were taken at $72 \mathrm{~h}$ postinoculation (hpi) with the Wt, Ko14 and Ko14-C strains. Also, Ko14 was inoculated on wounded leaves (Ko14-W). Bars = $20 \mu \mathrm{m}$. E to H, Plant defenses are heightened after infection with the Ko14 mutant. Production of antimicrobial compounds associated with plant cell-wall metabolism during Colletotrichum graminicola infection was evidenced by green autofluorescence $48 \mathrm{hpi}$. Bars $=40 \mu \mathrm{m}(\mathrm{E}$ and $\mathrm{F})$. Accumulation of reactive oxygen species in plant cells was assayed by diaminobenzidine-staining in response to the pathogen $72 \mathrm{hpi}(\mathrm{G}$ and $\mathrm{H})$. In the Wt strain, $\mathrm{H}_{2} \mathrm{O}_{2}$ is accumulated in vesicles surrounding fungal hyphae (arrows) while, in the case of mutant Ko14, the production of $\mathrm{H}_{2} \mathrm{O}_{2}$ is dispersed in the whole plant cell. Bars = $10 \mu \mathrm{m}$. I to $\mathbf{L}$, Lactophenol blue-staining of leaf infection sites 72 hpi. In contrast to Wt, no Ko14 hyphae are observed inside the plant cells. Bars $=80 \mu \mathrm{m}$ (I and J). The normal development of the mutant strain is impaired, as no hypha develops underneath the appressorium. Bars $=5 \mu \mathrm{m}(\mathrm{K}$ and $\mathrm{L})$. $\mathbf{M}$ to $\mathbf{P}$, Plant epidermis stops the penetration of the Ko14 mutant strain. Similar to the Wt strain, the Ko14 mutant spores develop appressoria that accumulate pressure to penetrate cellophane membranes (Sakaguchi et al. 2010). Bars $=20 \mu \mathrm{m}(\mathrm{M}$ and $\mathrm{N}$ ). Leaf sections of infected leaves stained with toluidine blue O (60 hpi) show that penetration of epidermal cells by mutant Ko14 is stopped after a penetration peg is formed, but the wild type developed normal primary hyphae. Bars $=5$ $\mu \mathrm{m}(\mathrm{O}$ and $\mathrm{P}) . \mathrm{A}=$ appressorium, $\mathrm{PH}=$ primary hyphae, $\mathrm{H}=$ hyphae, and $\mathrm{PP}=$ penetration peg. In all cases, the micrographs are representatives of the analysis of at least 10 different infection sites, repeated three times. 
a similar role in plant pathogens (Hood et al. 1996; Mesarich et al. 2015; Rich and Ayala 2000). In fact, bacterial effectors that harbor ITR involved in host range modulation have already been described (Herbers et al. 1992).

CgEP1 and GLRG_09337 arose from a gene duplication followed by mutations and tandem, intragenic duplications. Since CgEP1 is only found in the Graminicola clade while GLRG_09337 is broadly distributed in the genus, it is likely that $\mathrm{CgEP} 1$ arose through partial or complete gene duplication in the common ancestor of the Graminicola clade. We
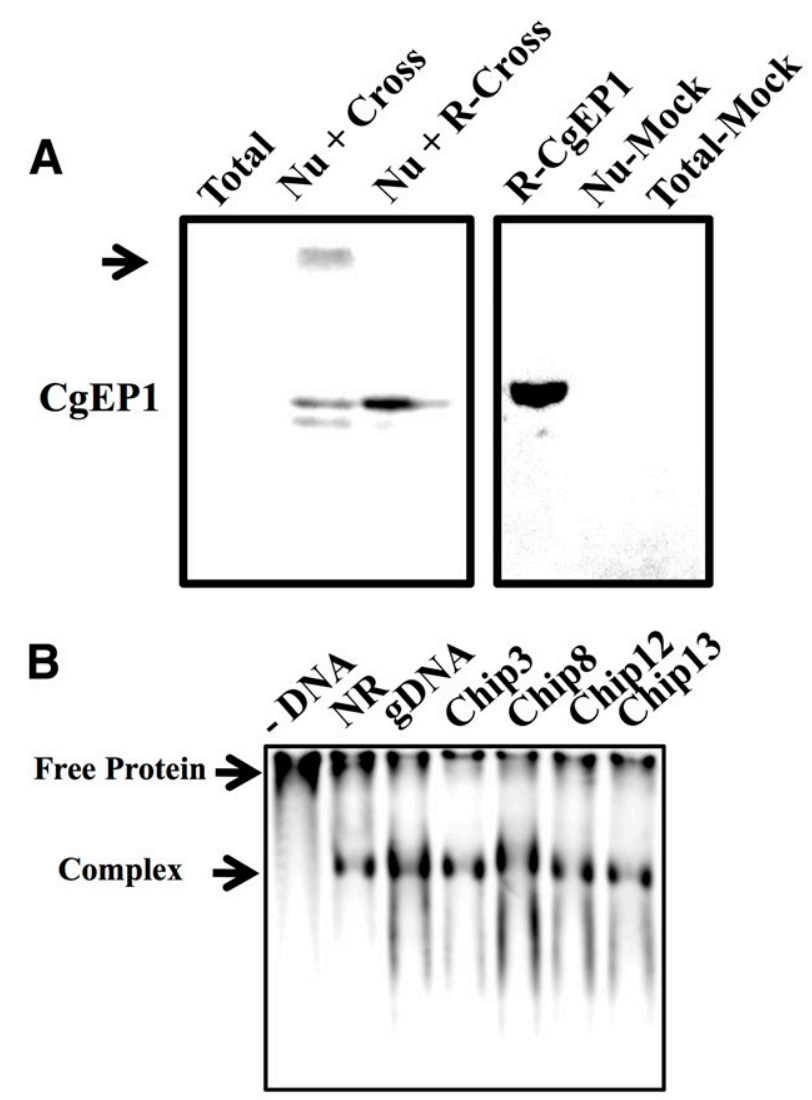

C
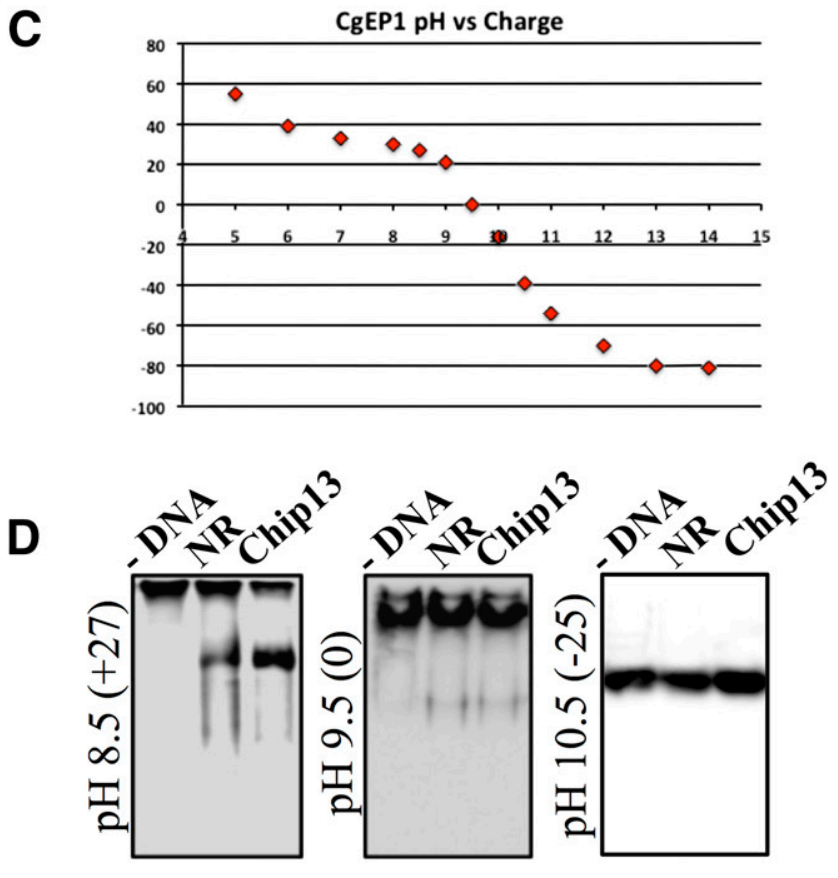

suggest that, following the duplication event, one gene copy was subject to intensive selective pressure, leading to a C-terminal region that is only slightly similar to its paralog. The repeat units of CgEP1 are nearly identical at the nucleotide level, suggesting a recent origin of the duplications. Alternatively, other evolutionary processes, such as concerted evolution, may be acting on the repeat units and maintaining homogeneity among them. Our analysis also revealed that there are codons subject to positive Darwinian selection located in the same position in each repeat unit, highlighting their functional importance during plant pathogenesis. These residues may be important for DNA target specificity or they may play roles in avoiding detection by the plant immune system. Their presence highlights the rapid appearance and adaptation of this new gene family in the Graminicola clade.

Functional characterization revealed that CgEp1 is a novel class of fungal effector necessary for $C$. graminicola to penetrate the maize epidermis and complete the maize infection process (Figs. 1 to 5). The epidermis is the first line of defense against invading pathogens and constitutes the first barrier that microorganisms have to invade, in both animal and plant hosts (Freeman and Beattie 2008; Gutowska-Owsiak and Ogg 2012; Javelle et al. 2011). In plants, it is known that complex physiological and biochemical responses are induced in the host epidermal cells during attack by pathogens, such as host gene-expression regulation, antimicrobial compound biosynthesis, cytoskeleton rearrangements, and even cell death (Freeman and Beattie 2008; Henty-Ridilla et al. 2014; Hof et al. 2014). Our hypothesis is that, in grass infecting Colletotrichum spp., CgEP1 binds to the host's DNA at the point it interrupts the expression of genes that are required for the immune response. The CgEP1 knockout strain (Ko14) is unable to infect intact plant tissue, but this effect is reverted when the leaf tissue is wounded, enabling the fungus to bypass the epidermis (Fig. 4). Strains impaired in CgEP1 expression are arrested in the epidermal cell layer during host penetration attempts (Fig. $4 \mathrm{O}$ and $\mathrm{P}$ ). The immune responses in the epidermis cells are key components for a heightened immunological state against the hemibiotrophic fungus. However,

Fig. 5. Protein charge is crucial for CgEP1 binding to host genomic DNA A, CgEP1 forms a high molecular weight complex in the nucleus of maize cells infected with Colletotrichum graminicola. Nuclear protein extracts from leaves infected with $C$. graminicola were electrophoresed in $10 \%$ acrylamide denaturing gels (sodium dodecyl sulfate-polyacrylamide gel electrophoresis) and were transferred to nitrocellulose membranes, and CgEP1 was detected using anti-CgEP1 antibodies. In nuclear extracts, CgEP1 was detected as a high molecular weight complex (arrow), after protein cross-linking using formaldehyde (Nu+Cross). When the crosslinking was reverted, $\mathrm{CgEP} 1$ was detected as a free protein $(\mathrm{Nu}+\mathrm{R}-\mathrm{Cross})$. In leaf protein extracts (Total), CgEP1 is a minor protein below the detection limits. B, CgEP1 binds DNA independently of target sequence. As sequence specificity control, samples were incubated in the presence of maize genomic DNA (gDNA) or salmon sperm DNA (NR). Chip3, Chip8, Chip12, and Chip13 correspond to DNA fragments cloned after chromatin immunoprecipitation experiments. After binding reaction, samples were electrophoresed on acrylamide native gels and were transferred onto nitrocellulose membranes and CgEP1 was immunodetected. When the protein interacts with DNA, the highly positive charge is reduced or neutralized so that the protein mobility increases (arrows). C, Prediction of $\mathrm{pH}$ dependence of CgEP1 protein charge. The graph depicts charge changes ( $y$ axis) versus $\mathrm{pH}$ values ( $x$ axis). The values were predicted using Expasy tools. D, Protein-DNA binding at different $\mathrm{pH}$ levels. Using the purified recombinant CgEP1 and purified DNA fragment corresponding to the Chip13 clone, the binding reactions were electrophoresed in native gels at $\mathrm{pH} 8.5,9.5$, and 10.5 , conditions in which the protein charge is predicted to be $+27,0$, and -25 , respectively. Increasing the $\mathrm{pH}$, the protein charge changes and the protein is unable to bind DNA. 
C. graminicola (and other Colletotrichum species) are able to overcome those defensive responses, and our results suggest that CgEP1 has an active role in this task. In the hemibiotroph $M$. oryzae, it has been shown that pathogenesis in leaves and roots are uncoupled processes regulated by tissue-specific effectors (Marcel et al. 2010; Skibbe et al. 2010; Tucker et al. 2010). Similar conclusions were made for the $U$. maydismaize pathosystem, in which it was suggested that individual fungal effector proteins contribute to fungal virulence in an organ-specific manner (Schilling et al. 2014). However, CgEP1 plays a more general role in pathogenesis and is essential for pathogenicity in different maize tissues. Our results suggest that effectors play important roles at different regulatory levels and that a single effector may be enough to allow for disease development in distinct host tissues. In the case of anthracnose, it is likely that $\mathrm{CgEP} 1$ acts at a higher regulatory level than organ specificity, interfering with general host responses common to leaf, stalk, and root infection (Fig. 3A to D). CgEP1 is expressed even before the fungus penetrates the epidermis, being found even in ungerminated spores (Fig. 2B). In addition, CgEP1 null mutants can form normal appressoria that can penetrate cellophane, yet are unable to cause disease. This suggests a role for CgEP1 in the establishment of biotrophy as soon as the fungus penetrates the epidermis and that it is required during the whole biotrophic stage of development.

When invading the host, effectors play essential roles, helping the pathogen to overcome the host immune system. For instance, the fungal effectors SLP1 and Pep1 interfere with natural defense mechanisms activated by the plant hosts (Doehlemann et al. 2009; Mentlak et al. 2012). CgEP1 is delivered during the biotrophic stage into the nucleus of maize cells in which it binds to chromatin (Fig. 5). Our results show that the DNA-binding capacity of CgEP1 is nonspecific and that it likely binds to hundreds of target sites in the $Z$. mays genome. Searches for conserved sequence motifs among the sequences from the ChIP-cloning experiment failed to identify a common binding motif, suggesting that either CgEP1 does not target a specific motif or that the target motif is common. We identified 58 genes that have significant similarity to the cloned ChIP sequences within the region 2,000 bp upstream of the coding sequence. Many of these genes are uncharacterized and have no known function. Of the few with hypothetical functions, four are TFs with homology to TFs having roles in plant responses to biotic and abiotic stresses in other plant species. One has homology to zinc finger-containing TFs, which are known to mediate PAMP-triggered immunity in Arabidopsis (Ciftci-Yilmaz and Mittler 2008; MaldonadoBonilla et al. 2014). Another is a NAC domain-containing TF. An increasing amount of evidence is showing that NAC proteins play important roles in the regulation of plant defense responses to various types of pathogens, including Colletotrichum spp. (Jensen et al. 2008; Liu et al. 2014; Shan et al. 2015; Voitsik et al. 2013). The other two are a WRKY- and MADs box-containing TF, both of which are implicated in various physiological processes, including responses to biotic and abiotic stress (Arora et al. 2007; Nuruzzaman et al. 2013; Pandey and Somssich 2009). While the DNA-binding activity of CgEP1 is nonspecific, these results show that it has the capacity to bind upstream of TFs that likely regulate a variety of cellular processes, including pathogenicity. We hypothesize that, like a shotgun that hits its target with hundreds of projectiles, CgEP1 may interfere with the transcription of many host genes, some of which are components of the immune system. The lack of a specific DNA-binding motif may be an adaptation that prevents the host from evolving mutations that inhibit CgEP1 binding. The nonspecific DNA binding capacity of CgEP1 may also be a consequence of its relatively recent appearance in the Graminicola clade of Colletotrichum spp.

CgEP1 appears to function as a bacterial nucleomodulin (Bierne and Cossart 2012), translocating to the host nucleus and interfering with genes involved in the immune response. Maize plants respond to infection by $\mathrm{CgEP} 1$ null mutant strains with a strong oxidative response (Fig. 4), suggesting that CgEP1 works by repressing the oxidative burst. To better understand the role of CgEP1 in the suppression of the oxidative burst, future studies will focus on transcriptomic studies of maize infected with the wild-type strain of C. graminicola (M1.001) and the CgEP1 null mutant during the early stages of infection.

There are an increasing number of nuclear effectors that are being identified in filamentous plant pathogens as well as an increasing number of plant defense signaling components. The diversity of nuclear effectors present in filamentous fungi and other plant pathogens highlights the variety of plant-immunity regulatory networks that effectors can target. CgEP1 is wellconserved in the Graminicola clade including pathogens of many of the most important agricultural crops and, therefore, could be a promising target for novel fungicides in plant protection. Pharmacological treatments to abolish the effect of this effector family could be highly specific and innocuous for humans and other animals but successful in controlling anthracnose development in a variety of important crops.

Our results demonstrate the importance of nuclear effectors for plant host infection and disease development. In the case of CgEP1, we demonstrate the importance of this protein to overcome the primary plant defenses activated in epidermal cells. The epidermis of maize leaves is able to execute an aggressive immune response to prevent pathogenic infections but, by using effector proteins, fungal pathogens neutralize such plant defensive responses (ETS). In this report, we provide insights into the potential of genome-wide strategies to uncover novel effector proteins in pathogenic fungi. Further research on these high-priority targets will reveal which ones show the highest biotechnological capabilities for controlling plant disease.

\section{MATERIALS AND METHODS}

Maize and $C$. graminicola culture conditions.

Colletotrichum graminicola wild-type strain M1.001-BH (also reported as CgM2) (Forgery et al. 1978) and its derivative GFP-tagged strain (Sukno et al. 2008) were used in this article. Liquid cultures were incubated with orbital shaking in minimal medium supplemented with $1 \%$ sucrose as described by Horbach et al. (2009). Susceptible maize inbred line Mo940 was grown as previously described (Vargas et al. 2012). Transgenic maize plants expressing a GFP-tagged version of histone H1B was used for subcellular localization assays (Maize Cellgenomics database).

\section{Genomic DNA purification, Southern blots, and DNA sequencing.}

Total genomic DNA was purified from mycelium grown in liquid cultures, using the protocol of Baek and Kenerley (1998). Southern blot analyses were performed with $10 \mu \mathrm{g}$ of genomic DNA digested with NheI and SpeI or NdeI. The DNA was electrophoresed in $0.8 \%$ agarose gels and was transferred to Amersham HyBond-N (GE Healthcare) membranes. The probes were prepared by PCR, using primers $3887 \mathrm{O} 3 \mathrm{R}$ and 3887O4F. The probe was labeled using a DIG DNA labeling kit (Roche Diagnostics), following the manufacturer's instructions. The membranes were hybridized and washed under high stringency as described by Sambrook and Russell (2001). 
The CgEP1 orthologs from C. cereale, C. falcatum, and C. sublineola were amplified by PCR, using primers 3887O3R and $3887 \mathrm{O} 4 \mathrm{~F}$. The PCR products were purified, were cloned into vector pGEM T Easy, and were sequenced. The sequences were submitted to the European Nucleotide Archive (WEBIN ID number Hx2000050423).

\section{Genetic modifications of $C$. graminicola M1.001-BH.}

CgEP1 was inactivated by gene deletion using DelsGate methodology (García-Pedrajas et al. 2008), using the plasmid pKW1, which includes a modification that allows for the deletion of any target gene and, simultaneously, the GFP-tagging of the strain (Supplementary Table S4). A gene replacement cassette was constructed by following the protocol of GarcíaPedrajas et al. (2008) and was transformed into $C$. graminicola protoplasts. To restore the normal expression of CgEP1 in the Ko14 mutant strain, a genomic fragment including 1,000 bp upstream and $1,000 \mathrm{bp}$ downstream of the coding region of CgEP1 was PCR-amplified and was transferred to pKW4, using Gateway technology. The resulting plasmid was transformed into protoplasts from the Ko14 mutant strain and was selected for nourceothricin resistance.

The constitutive expression of CgEP1 was achieved by cloning the CgEP1 coding region downstream of the constitutive promoter gpdA from Aspergillus nidulans in the pRFHUE vector, using the USER Friendly cloning system (Frandsen et al. 2008). The CgEP1 coding region was PCR-amplified using primers 3887O3R and 3887O3F (Supplementary Table S5) to generate the expression vector. The genomic region containing the promoter of CgEP1 (1,000 bp upstream of the ATG) was cloned upstream of the GFP cassette. Using Gateway technology, the promoter regions to study were PCR-amplified (primers p-3887-GFP Fw and 2_3887) and, then, transferred to vector $\mathrm{pKW} 3$. A control for constitutive gene expression was generated using the promoter region of the constitutively expressed gene $C g T u b 4$ (the promoter region was PCR-amplified using primers TubFus1 and TubFus2.

The full-length cDNA from CgEP1 was ligated in frame to the coding region of the monomeric version of red fluorescent protein (mCherry), replacing the stop codon of CgEP1 with the start codon of mCherry. The chimeric molecule was PCR-amplified with the primers $3887 \mathrm{O} 3 \mathrm{R}$ and mCherry O4F cloned into plasmid pRFHUE, using the USER friendly cloning system (Frandsen et al. 2008). The expression of the translational fusion is driven by the constitutive promoter pgpdA. The plasmids were ectopically integrated into the C. graminicola genome by transformation and independent clones were selected for hygromycin resistance.

\section{Fungal protein preparation, SDS-PAGE, and Western blotting.}

Fungal proteins from culture supernatant were filtered on a $0.22-\mu \mathrm{m}$ membrane and were concentrated using Amicon Ultra Centrifugal Filters (3,000 molecular weight cut-off). Protein samples were separated on SDS-PAGE (Sambrook and Russell 2001) and were stained with a Coomassie blue or silver-staining kit (Thermo). Alternatively, after separation, the polypeptides were blotted onto a nitrocellulose membrane (HyBond C; Amersham Biosciences) for immunoassays (Sambrook and Russell 2001). Protein blots were probed with specific antibodies raised against $\mathrm{CgEP} 1$, anti-RbcL (Agrisera), or anti-H3 histone (Abcam). AntiCgEP1 sera was prepared after rabbit immunization with the synthetic peptide C-APTAPINDVAAPVEARAADFVDGAHLEARK (GeneCust Europe). The specificity of the antibodies was tested using total protein extracts from maize leaves and nuclear preparations of mock-inoculated plants; in both cases, no signal was retrieved after Western blotting (data not shown).

\section{ChIP-cloning assays.}

Maize leaves (5 g) containing approximately 100 C. graminicola infection sites per leaf were collected 48 hpi and were fixed using a $1 \%$ formaldehyde solution, as previously described (Ricardi et al. 2010). The infected and cross-linked tissue was further used to isolate nuclei. Nuclear preparations were sonicated with five rounds of 10-s pulse, using $15 \%$ intensity of a microtip sonicator (Bandelin Sonopuls Sonicator). The samples were used for ChIP or protein-protein interaction experiments.

Sheared chromatin (approximately $20 \mu \mathrm{g}$ ) was immunoprecipitated using purified polyclonal antibodies (immunoglobulinG) anti-CgEP1, following the method reported by Ricardi et al. (2010). The recovered DNA was treated with T4-DNA polymerase (Roche) to fill the ends of sheared molecules, was ligated to double-stranded adaptor (CTAA TACGACTCACTATAGGGCTCGAGCGGCCGCCCGGG CAGGT) and excess adaptor was removed using spin columns. Purified DNA was PCR-amplified using internal primers matching the adaptor (TCGAGCGGCCGCCCGGGCAGGT). The PCR products were separated on agarose gels, were extracted, were ligated into the pGEM-T Easy vector system (Promega), and were transformed into E. coli. The transformants were further analyzed by restriction assays and DNA sequencing.

\section{Pathogenicity and appressorium penetration assays.}

In vivo leaf blight assays were done with susceptible maize inbred line Mo940 (Warren et al. 1975, 1976) following the protocol of Vargas et al. (2012), and virulence was quantified by measuring the area of necrotic lesions. Alternatively, spore solutions $\left(10^{6}\right.$ spores per milliliter) were uniformly sprayed on the leaf surface, were incubated in a moisture chamber $(16 \mathrm{~h})$, and were transferred to a growth chamber until disease development. In vitro stalk-rot assays were performed as previously optimized (Thon et al. 2000). Maize leaf sheaths were infected following the protocol previously described for rice but adapted for maize plants (Koga et al. 2004). The pathogenicity assays were repeated three times, using five plants for each strain.

Root infection assays were performed covering maize roots with $C$. graminicola mycelium. The fungal strains were plated in the center of nitrocellulose filters placed on top of a petri dish containing potato dextrose agar. After 5 days, the filters were cut into strips that were placed on top of the roots. Three days after germination, the emerging maize roots were inoculated with the filter strips and were incubated in a dark moisture chamber at room temperature. Roots sections were stained with propidum iodine (Sigma) and were observed with a confocal microscope.

The mechanical penetration of cellophane membrane by appressoria was tested using the protocol of Sakaguchi et al. (2010).

\section{RNA samples, reverse transcription, and quantitative PCR assays.}

Total RNA from infection sites was extracted using TRIZOL reagent (Gibco-BRL), following the protocol provided by the manufacturer. RNA quality was verified after electrophoresis on agarose gels and ethidium bromide staining. cDNA synthesis was performed using $5 \mu \mathrm{g}$ of total RNA, Moloney murine leukemia virus reverse transcription (Promega) and oligo-dT primers. Prior to the reverse transcription (RT), RNA samples had been treated with Turbo DNA-Free DNAse (Ambion, Austin Texas) to remove trace amounts of genomic DNA. Quantitative (q)RT-PCR experiments were carried out following RT of RNA. The qRT-PCR samples were collected from three independent pathogenicity assays. PCR reactions were performed using specific primers for each gene assayed, the constitutively expressed histone $\mathrm{H} 3$, and $\beta$-tubulin, for normalization of $C$. graminicola genes. The sizes of the PCR products were confirmed by gel electrophoresis and the SYBer-green detection was verified by 
ensuring that the melting curves contained only one peak. All of the primer pairs used showed efficiencies of at least $95 \%$. The relative expression level of the test genes were calculated using the comparative cycle threshold (Ct) method. (Livak et al. 1995) All Ct calculations and statistical analyses were performed using the StepOne software v2.2.2.

\section{Heterologous protein expression and purification.}

The coding region of the mature version of CgEP1 was PCRamplified (primers HEPetFw and 3887HERv) and was cloned into pGEM T Easy and subcloned in frame with a (His) 6 tag into pET28TEV. The resulting plasmid was transformed into E. coli BL21pLysDE3 and protein expression was induced overnight at $18^{\circ} \mathrm{C}$. The recombinant protein was purified using HisPur Cobalt resin (Thermo Scientific) and was eluted with $100 \mathrm{mM}$ imidazol, following the protocol suggested by the manufacturer.

\section{Protein-DNA interaction assays.}

CgEP1 DNA-binding capacity was tested in reaction mixtures containing $5 \mu \mathrm{g}$ of purified recombinant CgEP1, $100 \mathrm{ng}$ DNA, $1 \times \mathrm{Taq}$ polymerase buffer (Biotools), $10 \mu \mathrm{g}$ bovine serum albumin, $1 \times$ halt protease inhibitor cocktail (Thermo Scientific), $1 \mathrm{mM}$ dithiothreitol, and $20 \%$ glycerol. The samples were incubated at $20^{\circ} \mathrm{C}$ for $20 \mathrm{~min}$ and were electrophoresed on nondenaturing $6 \%$ acrylamide gels (containing $0.5 \%$ tris-borateEDTA and $2.5 \%$ glycerol). After electrophoresis, the gels were incubated $10 \mathrm{~min}$ in $1 \%$ SDS at room, and proteins were blotted onto nitrocellulose membranes for immunodetection of CgEP1.

\section{Microscopy and image processing.}

Microscopic analysis was performed using a Leica DMLB fluorescence microscope, a Leica DG300F digital camera, and Leica IM1000 software. This instrument was used for bright field and fluorescence microscopy. GFP was excited at $588 \mathrm{~nm}$ and green fluorescence was detected at $610 \mathrm{~nm}$. Confocal microscope images were taken with a Leica TCS SP2 laser scanning spectral confocal microscope. Projections were generated from adjusted individual channels in the image stacks using Leica software.

\section{Bioinformatics.}

Secreted proteins were identified with SignalP 4.0. The predicted signal peptide was removed from the protein sequence (using SignalP4.0) and the mature protein was scanned with WoLF-PSORT, using the settings for plants (Horton et al. 2007). The highest scoring subcellular prediction was used without a score threshold. Proteins classified as species-specific were identified by performing a BLAST search to the Genank $\mathrm{nr}$ database. The BLAST results were inspected manually to determine homology. The BLAST and InterPro searches were completed using Geneious 5.6 (Kearse et al. 2012).

Orthologous transcript sequences of CgEP1 in 15 isolates of Colletotrichum graminicola were aligned using MUSCLE (Edgar 2004) and protein alignment gaps were mapped to DNA using PyCogent (Knight et al. 2007). The CodeML program from the PAML package (Yang 2007) was used to investigate patterns of positive selection. Selective pressure was measured through $\omega=\mathrm{dN} / \mathrm{dS}$ ratio, where $\mathrm{dN}$ and $\mathrm{dS}$ represent the nonsynonymous and synonymous substitution rates, respectively. Orthologous sequences showing $\omega=1,<1$, or $>1$ are assumed to be evolving under neutral evolution, negative selection, or positive selection, respectively (Yang and Bielawski 2000). The $\omega$ ratios were analyzed under different codon models and, then, hypotheses were tested using the likelihood ratio test (Anisimova et al. 2001). The Bayes empirical Bayes method was used to calculate the posterior probabilities for each codon to belong to a site class of positive selection under model M2 and M8 (Yang et al. 2005).
To determine the architecture of $\mathrm{CgEP} 1$, a multiple sequence alignment was performed with 19 Colletotrichum proteins, using MAFFT multiple aligner (Katoh et al. 2002). CgEP1 was used as a query in BLAST (Altschul et al. 1997). We also used the program phmmer of HMMER (Finn et al. 2011) versus the $\mathrm{nr}$ database to identify additional sequences that escaped to the other methods. RADAR (Heger and Holm 2000) was used to to detect repetitive patterns. Protein secondary structure was predicted using the software Geneious (Kearse et al. 2012).

The species tree was reconstructed using the five genes (ITS, CHS-1, His3, ACT, and Tub2) reported by O'Connell et al. (2012). The sequences were concatenated in Geneious (Kearse et al. 2012) and were aligned with MAFFT (Katoh et al. 2002). The tree was reconstructed with PhyML (Guindon and Gascuel 2003) and MrBayes (Ronquist and Huelsenbeck 2003). A total of 500 replicates were used in PhyML to calculate the percentage of bootstrap. The convergence was checked using a sample frequency of 1,000 generations. A burn-in of $25 \%$ was excluded for the posterior probability tree.

\section{ACKNOWLEDGMENTS}

This research was supported by funds from the Ministry of Economy and Competitiveness of Spain (grants AGL2011-29446 and AGL2012-34139) and grant SA-165U13 from the Junta de Castilla y León, Spain. W. A. Vargas is a member of the Research Career of the Consejo Nacional de Investigaciones Científicas y Técnicas of Argentina. We thank D. Prusky and R. O'Connell for critical discussion on this work, J. Manners for providing genomic DNA from Australian isolates, J. Parker for providing the pEXGFP plasmid, and M. García-Pedraja for providing us with the DelsGate plasmid vectors. We thank everyone who contributed fungal cultures that were used in this study. We also thank R. Baroncelli for providing access to unpublished data.

\section{LITERATURE CITED}

Altschul, S. F., Madden, T. L., Schäffer, A. A., Zhang, J., Zhang, Z., Miller, W., and Lipman, D. J. 1997. Gapped BLAST and PSI-BLAST: A new generation of protein database search programs. Nucleic Acids Res. 25: 3389-3402.

Anisimova, M., Bielawski, J. P., and Yang, Z. 2001. Accuracy and power of the likelihood ratio test in detecting adaptive molecular evolution. Mol. Biol. Evol. 18:1585-1592.

Arora, R., Agarwal, P., Ray, S., Singh, A. K., Singh, V. P., Tyagi, A. K., and Kapoor, S. 2007. MADS-box gene family in rice: Genome-wide identification, organization and expression profiling during reproductive development and stress. BMC Genomics 8:242.

Baek, J. M., and Kenerley, C. M. 1998. The arg2 gene of Trichoderma virens: Cloning and development of a homologous transformation system. Fungal Genet. Biol. 23:34-44.

Bailey, J. A., and Jeger, M. J., eds. 1992 Colletotrichum: Biology, Pathology and Control. CAB International, Wallingford, U.K.

Bellafiore, S., Shen, Z., Rosso, M.-N., Abad, P., Shih, P., and Briggs, S. P. 2008. Direct identification of the Meloidogyne incognita secretome reveals proteins with host cell reprogramming potential. PLoS Pathog. 4: e1000192.

Bergstrom, G. C., and Nicholson, R. L. 1981. Invertase in the spore matrix of Colletotrichum graminicola. J. Phytopathol. 102:139-147.

Bergstrom, G. C., and Nicholson, R. L. 1999. The biology of corn anthracnose: Knowledge to exploit for improved management. Plant Dis. 83:596-608.

Bierne, H., and Cossart, P. 2012. When bacteria target the nucleus: The emerging family of nucleomodulins. Cell. Microbiol. 14:622-633.

Bogdanove, A. J., and Voytas, D. F. 2011. TAL effectors: Customizable proteins for DNA targeting. Science 333:1843-1846.

Bolton, M. D., van Esse, H. P., Vossen, J. H., de Jonge, R., Stergiopoulos, I., Stulemeijer, I. J. E., van den Berg, G. C., Borrás-Hidalgo, O., Dekker, H. L., de Koster, C. G., de Wit, P. J., Joosten, M. H., and Thomma, B. P. 2008. The novel Cladosporium fulvum lysin motif effector Ecp6 is a virulence factor with orthologues in other fungal species. Mol. Microbiol. 69:119-136.

Busch, H. 1965. Histones and Other Nuclear Proteins. Academic Press, New York.

Chen, S., Songkumarn, P., Venu, R. C., Gowda, M., Bellizzi, M., Hu, J., Liu, W., Ebbole, D., Meyers, B., Mitchell, T., and Wang, G.-L. 2013. 
Identification and characterization of in planta-expressed secreted effector proteins from Magnaporthe oryzae that induce cell death in rice. Mol. Plant-Microbe Interact. 26:191-202.

Ciftci-Yilmaz, S., and Mittler, R. 2008. The zinc finger network of plants. Cell. Mol. Life Sci. 65:1150-1160.

Crouch, J. A., and Beirn, L. A. 2009. Anthracnose of cereals and grasses. Fungal Divers. 39:19-44.

Doehlemann, G., van der Linde, K., Assmann, D., Schwammbach, D., Hof, A., Mohanty, A., Jackson, D., and Kahmann, R. 2009. Pep1, a secreted effector protein of Ustilago maydis, is required for successful invasion of plant cells. PLoS Pathog. 5:e1000290.

Edgar, R. C. 2004. MUSCLE: Multiple sequence alignment with high accuracy and high throughput. Nucleic Acids Res. 32:1792-1797.

Fellbrich, G., Romanski, A., Varet, A., Blume, B., Brunner, F., Engelhardt, S., Felix, G., Kemmerling, B., Krzymowska, M., and Nürnberger, T. 2002. NPP1, a Phytophthora-associated trigger of plant defense in parsley and Arabidopsis. Plant J. 32:375-390.

Finn, R. D., Clements, J., and Eddy, S. R. 2011. HMMER web server: Interactive sequence similarity searching. Nucl. Acids Res. 39:W29-W37.

Forgery, W., Blanco, M., and Loegering, W. 1978. Differences in pathological capabilities and host specificity of Colletotrichum graminicola on Zea mays (maize). Plant Dis. Rep. 62:573-576.

Frandsen, R. J., Andersson, J. A., Kristensen, M. B., and Giese, H. 2008. Efficient four fragment cloning for the construction of vectors for targeted gene replacement in filamentous fungi. BMC Mol. Biol. 9:70.

Freeman, B. C., and Beattie, G. A. 2008. An overview of plant defenses against pathogens and herbivores. Plant Health Instr. doi:10.1094/PHI-I2008-0226-01. Published online.

Gan, P., Ikeda, K., Irieda, H., Narusaka, M., O’Connell, R. J., Narusaka, Y., Takano, Y., Kubo, Y., and Shirasu, K. 2013. Comparative genomic and transcriptomic analyses reveal the hemibiotrophic stage shift of Colletotrichum fungi. New Phytol. 197:1236-1249.

García-Pedrajas, M. D., Nadal, M., Kapa, L. B., Perlin, M. H., Andrews, D. L., and Gold, S. E. 2008. DelsGate, a robust and rapid gene deletion construction method. Fungal Genet. Biol. 45:379-388.

Guindon, S., and Gascuel, O. 2003. A simple, fast, and accurate algorithm to estimate large phylogenies by maximum likelihood. Syst. Biol. 52:696-704.

Gutowska-Owsiak, D., and Ogg, G. S. 2012. The epidermis as an adjuvant. J. Invest. Dermatol. 132:940-948.

Henty-Ridilla, J. L., Li, J., Day, B., and Staiger, C. J. 2014. ACTIN DEPOLYMERIZING FACTOR4 regulates actin dynamics during innate immune signaling in Arabidopsis. Plant Cell 26:340-352.

Herbers, K., Conrads-Strauch, J., and Bonas, U. 1992. Race-specificity of plant resistance to bacterial spot disease determined by repetitive motifs in a bacterial avirulence protein. Nature 356:172-174.

Heger, A., and Holm, L. 2000. Rapid automatic detection and alignment of repeats in protein sequences. Proteins 41:224-237.

Hof, A., Zechmann, B., Schwammbach, D., Hückelhoven, R., and Doehlemann, G. 2014. Alternative cell death mechanisms determine epidermal resistance in incompatible barley-Ustilago interactions. Mol. Plant-Microbe Interact. 27:403-414.

Hogenhout, S. A., Van der Hoorn, R. A. L., Terauchi, R., and Kamoun, S. 2009. Emerging concepts in effector biology of plant-associated organisms. Mol. Plant-Microbe Interact. 22:115-122.

Hood, D. W., Deadman, M. E., Jennings, M. P., Bisercic, M., Fleischmann, R. D., Venter, J. C., and Moxon, E. R. 1996. DNA repeats identify novel virulence genes in Haemophilus influenzae. Proc. Natl. Acad. Sci. U.S.A. 93:11121-11125.

Horbach, R., Graf, A., Weihmann, F., Antelo, L., Mathea, S., Liermann, J. C., Opatz, T., Thines, E., Aguirre, J., and Deising, H. B. 2009. Sfp-type $4^{\prime}$-phosphopantetheinyl transferase is indispensable for fungal pathogenicity. Plant Cell 21:3379-3396.

Horton, P., Park, K.-J., Obayashi, T., Fujita, N., Harada, H., Adams-Collier, C. J., and Nakai, K. 2007. WoLF PSORT: Protein localization predictor. Nucleic Acids Res. 35:W585-W587.

Irieda H., Maeda H., Akiyama K., Hagiwara A., Saitoh H., Uemura A., Terauchi R., Takano Y. 2014. Colletotrichum orbiculare secretes virulence effectors to a biotrophic interface at the primary hyphal neck via exocytosis coupled with SEC22-mediated traffic. Plant Cell 26:2265-2281.

Javelle, M., Vernoud, V., Rogowsky, P. M., and Ingram, G. C. 2011. Epidermis: The formation and functions of a fundamental plant tissue. New Phytol. 189:17-39.

Jensen, M. K., Hagedorn, P. H., de Torres-Zabala, M., Grant, M. R., Rung, J. H., Collinge, D. B., and Lyngkjaer, M. F. 2008. Transcriptional regulation by an NAC (NAM-ATAF1,2-CUC2) transcription factor attenuates ABA signalling for efficient basal defence towards Blumeria graminis f. sp. hordei in Arabidopsis. Plant J. 56:867-880.

Jeon, J., Park, S.-Y., Chi, M.-H., Choi, J., Park, J., Rho, H.-S., Kim, S., Goh, J., Yoo, S., Choi, J., Park, J.-Y., Yi, M., Yang, S., Kwon, M.-J., Han,
S.-S., Kim, B. R., Khang, C. H., Park, B., Lim, S.-E., Jung, K., Kong, S., Karunakaran, M., Oh, H.-S., Kim, H., Kim, S., Park, J., Kang, S., Choi, W.-B., Kang, S., and Lee, Y.-H. 2007. Genome-wide functional analysis of pathogenicity genes in the rice blast fungus. Nat. Genet. 39:561565 .

Jones, J. D. G., and Dangl, J. L. 2006. The plant immune system. Nature 444:323-329.

Kanzaki, H., Yoshida, K., Saitoh, H., Fujisaki, K., Hirabuchi, A., Alaux, L., Fournier, E., Tharreau, D., and Terauchi, R. 2012. Arms race coevolution of Magnaporthe oryzae AVR-Pik and rice Pik genes driven by their physical interactions. Plant J. 72:894-907.

Katoh, K., Misawa, K., Kuma, K., and Miyata, T. 2002. MAFFT: A novel method for rapid multiple sequence alignment based on fast Fourier transform. Nucleic Acids Res. 30:3059-3066.

Kearse, M., Moir, R., Wilson, A., Stones-Havas, S., Cheung, M., Sturrock, S., Buxton, S., Cooper, A., Markowitz, S., Duran, C., Thierer, T., Ashton, B., Meintjes, P., and Drummond, A. 2012. Geneious basic: An integrated and extendable desktop software platform for the organization and analysis of sequence data. Bioinformatics 28:1647-1649.

Kemen, E., Kemen, A. C., Rafiqi, M., Hempel, U., Mendgen, K., Hahn, M. and Voegele, R. T. 2005. Identification of a protein from rust fungi transferred from haustoria into infected plant cells. Mol. Plant-Microbe Interact. 18:1130-1139.

Khang, C. H., Berruyer, R., Giraldo, M. C., Kankanala, P., Park, S.-Y., Czymmek, K., Kang, S., and Valent, B. 2010. Translocation of Magnaporthe oryzae effectors into rice cells and their subsequent cellto-cell movement. Plant Cell 22:1388-1403.

Kleemann, J., Rincon-Rivera, L. J., Takahara, H., Neumann, U., Ver Loren van Themaat, E., van der Does, H. C., Hacquard, S., Stüber, K., Will, I., Schmalenbach, W., Schmelzer, E., and O'Connell, R. J. 2012. Sequentia delivery of host-induced virulence effectors by appressoria and intracellular hyphae of the phytopathogen Colletotrichum higginsianum. PLoS Pathog. 8:e1002643.

Kleemann, J., Takahara, H., Stüber, K., and O'Connell, R. 2008 Identification of soluble secreted proteins from appressoria of Colletotrichum higginsianum by analysis of expressed sequence tags. Microbiology 154:1204-1217.

Kloppholz, S., Kuhn, H., and Requena, N. 2011. A secreted fungal effector of Glomus intraradices promotes symbiotic biotrophy. Curr. Biol. 21: 1204-1209

Knight, R., Maxwell, P., Birmingham, A., Carnes, J., Caporaso, J. G., Easton, B. C., Eaton, M., Hamady, M., Lindsay, H., Liu, Z., Lozupone, C., McDonald, D., Robeson, M., Sammut, R., Smit, S., Wakefield, M. J., Widmann, J., Wikman, S., Wilson, S., Ying, H., and Huttley, G. A. 2007. PyCogent: A toolkit for making sense from sequence. Genome Biol. 8:R171.

Koga, H., Dohi, K., Nakayachi, O., and Mori, M. 2004. A novel inoculation method of Magnaporthe grisea for cytological observation of the infection process using intact leaf sheaths of rice plants. Physiol. Mol. Plant Pathol. 64:67-72.

Liu, B., Ouyang, Z., Zhang, Y., Li, X., Hong, Y., Huang, L., Liu, S., Zhang, H., Li, D., and Song, F. 2014. Tomato NAC transcription factor SISRN1 positively regulates defense response against biotic stress but negatively regulates abiotic stress response. PLoS One 9:e102067.

Livak, K. J., Flood, S. J., Marmaro, J., Giusti, W., and Deetz, K. 1995. Oligonucleotides with fluorescent dyes at opposite ends provide a quenched probe system useful for detecting PCR product and nucleic acid hybridization. PCR Methods Appl. 4:357-362.

Maldonado-Bonilla, L. D., Eschen-Lippold, L., Gago-Zachert, S., Tabassum, N., Bauer, N., Scheel, D., and Lee, J. 2014. The Arabidopsis tandem zinc finger 9 protein binds RNA and mediates pathogenassociated molecular pattern-triggered immune responses. Plant Cell Physiol. 55:412-425.

Marcel, S., Sawers, R., Oakeley, E., Angliker, H., and Paszkowski, U. 2010. Tissue-adapted invasion strategies of the rice blast fungus Magnaporthe oryzae. Plant Cell 22:3177-3187.

Marian, C. O., Bordoli, S. J., Goltz, M., Santarella, R. A., Jackson, L. P., Danilevskaya, O., Beckstette, M., Meeley, R., and Bass, H. W. 2003. The maize single myb histone 1 gene, Smh1, belongs to a novel gene family and encodes a protein that binds telomere DNA repeats in vitro. Plant Physiol. 133:1336-1350.

Mentlak, T. A., Kombrink, A., Shinya, T., Ryder, L. S., Otomo, I., Saitoh, H., Terauchi, R., Nishizawa, Y., Shibuya, N., Thomma, B. P. H. J., and Talbot, N. J. 2012. Effector-mediated suppression of chitin-triggered immunity by Magnaporthe oryzae is necessary for rice blast disease. Plant Cell 24:322-335. 
Mesarich, C. H., Bowen, J. K., Hamiaux, C., and Templeton, M. D. 2015. Repeat-containing protein effectors of plant-associated organisms. Front. Plant Sci. 6:872.

Micali, C. O., Neumann, U., Grunewald, D., Panstruga, R., and O'Connell, R. 2011. Biogenesis of a specialized plant-fungal interface during host cell internalization of Golovinomyces orontii haustoria. Cell. Microbiol. 13:210-226.

Mims, C. W., and Vaillancourt, L. J. 2002. Ultrastructural characterization of infection and colonization of maize leaves by Colletotrichum graminicola, and by a $C$. graminicola pathogenicity mutant. Phytopathology 92:803-812.

Nuruzzaman, M., Sharoni, A. M., and Kikuchi, S. 2013. Roles of NAC transcription factors in the regulation of biotic and abiotic stress responses in plants. Front. Microbiol. 4:248.

O'Connell, R. J., Thon, M. R., Hacquard, S., Amyotte, S. G., Kleemann, J., Torres, M. F., Damm, U., Buiate, E. A., Epstein, L., Alkan, N., Altmüller, J., Alvarado-Balderrama, L., Bauser, C. A., Becker, C., Birren, B. W., Chen, Z., Choi, J., Crouch, J. A., Duvick, J. P., Farman, M. A., Gan, P., Heiman, D., Henrissat, B., Howard, R. J., Kabbage, M., Koch, C., Kracher, B., Kubo, Y., Law, A. D., Lebrun, M.-H., Lee, Y.-H., Miyara, I., Moore, N., Neumann, U., Nordström, K., Panaccione, D. G., Panstruga, R., Place, M., Proctor, R. H., Prusky, D., Rech, G., Reinhardt, R., Rollins, J. A., Rounsley, S., Schardl, C. L., Schwartz, D. C., Shenoy, N., Shirasu, K., Sikhakolli, U. R., Stüber, K., Sukno, S. A., Sweigard, J. A., Takano, Y., Takahara, H., Trail, F., van der Does, H. C., Voll, L. M., Will, I., Young, S., Zeng, Q., Zhang, J., Zhou, S., Dickman, M. B., SchulzeLefert, P., Ver Loren van Themaat, E., Ma, L.-J., and Vaillancourt, L. J. 2012. Lifestyle transitions in plant pathogenic Colletotrichum fungi deciphered by genome and transcriptome analyses. Nat. Genet. 44:1060-1065.

Pandey, S. P., and Somssich, I. E. 2009. The role of WRKY transcription factors in plant immunity. Plant Physiol. 150:1648-1655.

Panstruga, R. 2003. Establishing compatibility between plants and obligate biotrophic pathogens. Curr. Opin. Plant Biol. 6:320-326.

Perfect, S. E., and Green, J. R. 2001. Infection structures of biotrophic and hemibiotrophic fungal plant pathogens. Mol. Plant Pathol. 2:101-108.

Perfect, S. E., Hughes, H. B., O'Connell, R. J., and Green, J. R. 1999. Colletotrichum: A model genus for studies on pathology and fungalplant interactions. Fungal Genet. Biol. 27:186-198.

Petre, B., Saunders, D. G., Sklenar, J., Lorrain, C., Win, J., Duplessis, S., and Kamoun, S. 2015. Candidate effector proteins of the rust pathogen Melampsora larici-populina target diverse plant cell compartments. Mol. Plant-Microbe Interact. 28:689-700.

Plett, J. M., Kemppainen, M., Kale, S. D., Kohler, A., Legué, V., Brun, A., Tyler, B. M., Pardo, A. G., and Martin, F. 2011. A secreted effector protein of Laccaria bicolor is required for symbiosis development. Curr. Biol. 21:1197-1203.

Politis, D. J., and Wheeler, H. 1972. The perfect stage of Colletotrichum graminicola. Plant Dis. Rep. 56:1026-1027.

Pretsch, K., Kemen, A., Kemen, E., Geiger, M., Mendgen, K., and Voegele, R. 2013. The rust transferred proteins-a new family of effector proteins exhibiting protease inhibitor function. Mol. Plant Pathol. 14:96-107.

Prusky, D., Freeman, S., and Dickman, M. B., eds. 2000. Colletotrichum: Host Specificity, Pathology, and Host-Pathogen Interaction. APS Press, St. Paul, MN, U.S.A.

Redkar, A., Villajuana-Bonequi, M., and Doehlemann, G. Conservation of the Ustilago maydis Effector See1 in related smuts. Plant Signal. Behav. In press.

Ricardi, M. M., González, R. M., and Iusem, N. D. 2010. Protocol: Finetuning of a Chromatin Immunoprecipitation (ChIP) protocol in tomato. Plant Methods 6:11.

Rich, S. M., and Ayala, F. J. 2000. Population structure and recent evolution of Plasmodium falciparum. Proc. Natl. Acad. Sci. U.S.A. 97:69947001.

Rivas, S., and Genin, S. 2011. A plethora of virulence strategies hidden behind nuclear targeting of microbial effectors. Front. Plant Sci. 2: 104.

Ronquist, F., and Huelsenbeck, J. P. 2003. MrBayes 3: Bayesian phylogenetic inference under mixed models. Bioinformatics 19:1572-1574.

Sakaguchi, A., Miyaji, T., Tsuji, G., and Kubo, Y. 2010. A kelch repeat protein, Cokellp, associates with microtubules and is involved in appressorium development in Colletotrichum orbiculare. Mol. Plant-Microbe Interact. 23:103-111.
Sambrook, J., and Russell, D. W. 2001. Molecular Cloning: A Laboratory Manual, 3rd Ed. Cold Spring Harbor Laboratory Press, Cold Spring Harbor, NY, U.S.A.

Schilling, L., Matei, A., Redkar, A., Walbot, V., and Doehlemann, G. 2014. Virulence of the maize smut Ustilago maydis is shaped by organ-specific effectors. Mol. Plant Pathol. 15:8.

Shan, W., Chen, J., Kuang, J., and Lu, W. 2015. Banana fruit NAC transcription factor MaNAC5 cooperates with MaWRKYs to enhance expressions of pathogenesis-related genes against Colletotrichum musae. Mol. Plant Pathol. doi:10.1111/mpp.12281. Published online.

Skibbe, D. S., Doehlemann, G., Fernandes, J., and Walbot, V. 2010. Maize tumors caused by Ustilago maydis require organ-specific genes in host and pathogen. Science 328:89-92.

Stephenson, S. A., Hatfield, J., Rusu, A. G., Maclean, D. J., and Manners, J. M. 2000. CgDN3: An essential pathogenicity gene of Colletotrichum gloeosporioides necessary to avert a hypersensitive-like response in the host Stylosanthes guianensis. Mol. Plant-Microbe Interact. 13:929-941.

Sukno, S. A., García, V. M., Shaw, B. D., and Thon, M. R. 2008. Root infection and systemic colonization of maize by Colletotrichum graminicola. Appl. Environ. Microbiol. 74:823-832.

Thomas, J. O., and Travers, A. A. 2001. HMG1 and 2, and related 'architectural' DNA-binding proteins. Trends Biochem. Sci. 26:167-174.

Thon, M. R., Nuckles, E. M., and Vaillancourt, L. J. 2000. Restriction enzyme-mediated integration used to produce pathogenicity mutants of Colletotrichum graminicola. Mol. Plant-Microbe Interact. 13:1356-1365.

Torres, G., Frisella, P. D., Yousuf, S. J., Sarwar, S., Baldinger, L., Zakhary, S. M., and Leheste, J. R. 2008. A ChIP-cloning approach linking SIRT1 to transcriptional modificationof DNA targets. Biotechniques 44. doi: 10.2144/000112748. Published online.

Tucker, S. L., Besi, M. I., Galhano, R., Franceschetti, M., Goetz, S., Lenhert, S., Osbourn, A., and Sesma, A. 2010. Common genetic pathways regulate organ-specific infection-related development in the rice blast fungus. Plant Cell 22:953-972.

Vargas, W. A., Martín, J. M. S., Rech, G. E., Rivera, L. P., Benito, E. P., Díaz-Mínguez, J. M., Thon, M. R., and Sukno, S. A. 2012. Plant defense mechanisms are activated during biotrophic and necrotrophic development of Colletotricum graminicola in maize. Plant Physiol. 158:1342-1358.

Voitsik, A.-M., Muench, S., Deising, H. B., and Voll, L. M. 2013. Two recently duplicated maize NAC transcription factor paralogs are induced in response to Colletotrichum graminicola infection. BMC Plant Biol. 13:85.

Wang, C., Zhang, S., Hou, R., Zhao, Z., Zheng, Q., Xu, Q., Zheng, D., Wang, G., Liu, H., Gao, X., Ma, J.-W., Kistler, H. C., Kang, Z., and Xu, J.-R. 2011. Functional analysis of the kinome of the wheat scab fungus Fusarium graminearum. PLoS Pathog. 7:e1002460.

Warren, H. L. 1976. Relationship of Colletotrichum graminicola to foliar and kernel infection. Plant Dis. 60:1084-1086.

Warren, H. L., Nicholson, R. L., and Turner, M. T. 1975. Field reaction of corn inbreds to Colletotrichum graminicola. Plant Dis. 59:767-769.

Win, J., Chaparro-Garcia, A., Belhaj, K., Saunders, D. G. O., Yoshida, K., Dong, S., Schornack, S., Zipfel, C., Robatzek, S., Hogenhout, S. A., and Kamoun, S. 2012. Effector biology of plant-associated organisms: Concepts and perspectives. Cold Spring Harb. Symp. Quant. Biol. 77:235247.

Yang, Z. 2007. PAML 4: Phylogenetic analysis by maximum likelihood. Mol. Biol. Evol. 24:1586-1591.

Yang, Z., and Bielawski, J. P. 2000. Statistical methods for detecting molecular adaptation. Trends Ecol. Evol. Amst. 15:496-503.

Yang, Z., Wong, W. S. W., and Nielsen, R. 2005. Bayes empirical bayes inference of amino acid sites under positive selection. Mol. Biol. Evol. 22:1107-1118.

Yi, M., and Valent, B. 2013. Communication between filamentous pathogens and plants at the biotrophic interface. Annu. Rev. Phytopathol. 51:587611.

\section{AUTHOR-RECOMMENDED INTERNET RESOURCES}

J. Craig Venter Institute's Maize Cellgenomics database: http://maize.jcvi.org/cellgenomics/index.php

Expasy tools: www.expasy.org 